University of Rhode Island

DigitalCommons@URI

Open Access Master's Theses

1992

\title{
A COMPARISON OF THE SELF-CONCEPTS OF GIFTED PRE- ADOLESCENTS AND A NON-GIFTED PEER GROUP
}

\author{
Erika Natalie Gardiner \\ University of Rhode Island
}

Follow this and additional works at: https://digitalcommons.uri.edu/theses

\section{Recommended Citation}

Gardiner, Erika Natalie, "A COMPARISON OF THE SELF-CONCEPTS OF GIFTED PRE-ADOLESCENTS AND A NON-GIFTED PEER GROUP" (1992). Open Access Master's Theses. Paper 1718.

https://digitalcommons.uri.edu/theses/1718

This Thesis is brought to you for free and open access by DigitalCommons@URI. It has been accepted for inclusion in Open Access Master's Theses by an authorized administrator of DigitalCommons@URI. For more information, please contact digitalcommons-group@uri.edu. 
BF 723

G5

6273

1992

A COMPARISON OF THE SELF-CONCEPTS OF GIFTED PRE-ADOLESCENTS

AND A NON-GIFTED PEER GROUP

BY

ERIKA NATALIE GARDINER

A THESIS SUBMITTED IN PARTIAL FULFILLMENT OF THE

REQUIREMENTS FOR THE DEGREE OF

MASTER OF ARTS

IN

PSYCHOLOGY

UNIVERSITY OF RHODE ISLAND

$$
\begin{gathered}
1992 \\
\text { At }-1062573
\end{gathered}
$$




\begin{abstract}
This project investigated the multidimensional self-concepts of gifted and regular education fifth grade children. Potential differences in the ratings of Global, Physical, Social and Academic self-concept domains were investigated. Ratings of the importance of the specific domains were also examined. Participants consisted of 37 integrated gifted and 251 regular education classmates enrolled in the fifth grade of a suburban school district. Participants completed four selfreport measures: a variation of Kuhn and McPartland's "Who Am I?" task, an "Importance Scale" which examined the perceived importance of three self-concept domains, Marsh's (1981) SelfDescription Questionnaire, and a "Pie Chart" of the relative perceived importance of the three self-concept areas. Academic grouping and sex differences in the rating and importance of the self-concept domains were examined. Results indicated significant differences in the participants' ratings of their global and domain-specific selfconcepts and the importance of the specific domains. In accordance with previous research, gifted participants demonstrated Academic self-concepts that were significantly higher than those of the regular education sample. Significant differences were also found in the perceived importance of the domains for the gifted and regular education samples. Significant sex differences in the direction of traditional gender roles were found on all instruments. Results are discussed in terms of the influence of various socialization factors.
\end{abstract}




\section{Acknowledgements}

There are many people who have made completion of this project possible and to whom I give thanks. First, I would like to thank my major professor, Dr. Jerry Cohen, for his guidance and support. He has been a patient instructor, especially with the statistical portions of this project. I would also like to thank my additional committee members, Drs. Janet Kuhlberg, Jacqueline Wilk and Richard Sullivan for their constructive questions. Thanks are also extended to the administrators, teachers and staff of the Warwick School District for their interest in my research and facilitation of my data collection. A special thanks is extended to Richard Lloyd, who was my initial contact in the district, and made immeasurably helpful suggestions for my interactions with the district.

I would also like to offer a special thanks to my family and friends. Their support and interest has been invaluable while I have sought further knowledge in this area of interest. Their comments and jokes about my research have helped me along my journey. 
Table of Contents

Abstract ii

Acknowledgements iii

Table of Contents iv

List of Tables vi

List of Figures vii

Introduction 1

Method 13

Results 18

Discussion 43

References $\quad 50$

Appendix A: Research Participation Consent Form 55

Appendix B: Sample Participant Protocol 58

$\begin{array}{ll}\text { Bibliography } & 69\end{array}$ 
List of Tables

Table 1: Percentage of the Total Number of Sentences For Each

Category or the Who Am I Instrument

Table 2: Importance Scale Factors and Factor Loadings of Individual Items

Table 3: Source Table For the Repeated Measures ANOVA of the Importance Scale

Table 4: Mean Score and Standard Deviation By Sex For the Three Domains of the Importance Scale

Table 5: SDQ Subscales and Items

Table 6: Source Table For the ANOVA of the General-Self Variable

Table 7: Source Table For the Repeated Measures ANOVA For the Three Total Domains of the SDQ

Table 8: Mean Score and Standard Deviation By Sex On the Three Total Subscales of the SDQ

Table 9: Mean Score and Standard Deviation By Academic Grouping On the Three Total Subscales of the SDQ

Table 10: Source Table For the Repeated Measures ANOVA

On the Seven Domains of the SDQ

Table 11: Subscale Means For the Seven SDQ Areas

Table 12: Male Sample Pairwise Mean Differences 34

Table 13: Female Sample Pairwise Mean Differences 34

Table 14: ALAP Sample Pairwise Mean Differences 37

Table 15: Regular Education Sample Pairwise Mean Differences 37 


\section{List of Figures}

Figure 1: Mean Scores on the Seven SDQ Domains By Sex

Figure 2: Mean Scores on the Seven SDQ Domains By Academic Grouping

Figure 3: Mean Ranks For the Three Domains of the Pie Chart By Academic Grouping

Figure 4: Mean Ranks For the Three Domains of the Pie Chart By Sex 
The study of a child's self-concept is important in both psychology and education. Self-concept has been seen as the core of personality (Lecky, 1945) and the emergence of a positive selfconcept has been viewed as one of the objectives of the school system (Purkey, 1970). The study of the self-concept of gifted populations is particularly important in investigating the emergence and maintenance of gifted behaviors. Bailey (1971) has suggested that the self-concept affects all areas of the personality and either restricts or enhances the person's capacity to fulfill his or her native potential (cited in Maddux, Scheiber, \& Bass, 1982). Tannenbaum proposed that intelligence and self-concept work in a complementary fashion to produce gifted behaviors. A feedback loop is formed: if the individual thinks of him or herself as gifted, he or she will act in line with this self image and these high achievements will then further enhance the self-concept (Tannenbaum, 1986). Thus the self-concept of gifted children is important to study since it may be a substantial factor in influencing how well gifted children achieve their potential (Schneider, 1987).

However, in order to study self-concept, one must determine its definition. In a review of the research, Byrne (1984) reveals that no clear, concise, universally accepted operational definition of selfconcept exists. However, there appears to be wide acceptance of some aspects of self-concept by researchers. Researchers agree that in general terms, self-concept is an individual's perception of him or herself. This implies that self-concept is global and consistent across situations. In contrast, self-concept can also be viewed in a more specific manner implying that self-concept is made up of distinct 
categories. Winne and Marx (1981) proposed that these categories include academic, physical and social dimensions. In more specific terms, self-concept involves the attitudes, feelings, and knowledge of an individual's abilities, skills, appearance and social acceptability (Byrne, 1984; Jersild, 1965; Labenne \& Greene, 1969; West \& Fish, 1973).

Also important in the study of self-concept is the conceptualization of the construct within a theoretical framework. Cronbach and Meehl (1955) state that this corresponds to defining the nomological network of the construct. Nomological research involves internal and external examinations of the construct.

Internal analyses or within network studies involve an examination of the relationships among the particular facets of the construct. For example, the relationship between academic and physical dimensions of self-concept might be examined. External analyses or between network studies involve examining the relation of the construct under study with another construct, which has been proposed to be mutually exclusive. Examining the relationship between academic self-concept and academic achievement would be an example of an external analysis (cited in Byrne, 1984). In the present study, an internal, within network analysis of the dimensions of self-concept will be conducted.

\section{Models of Self-Concept}

Many models of self-concept exist. One of the oldest is the model proposed by William James in 1890 . He suggested that the selfconcept is composed of two distinct, yet conceptually related dimensions: the I-self and the Me-self. The I-self is the processor or 
"knower," whereas the Me-self is the product or what is known about oneself (Harter, 1988). More recently, Byrne (1984, p. 430) has proposed four possible models of self-concept, which differ in terms of their definition, situation-specificity, and interrelatedness of their dimensions:

1. Nomothetic - Self-concept is seen as a unidimensional phenomenon, where a global, general self-concept can explain behavior in a large number of settings and situations.

2. Hierarchical - Self-concept is seen as being comprised of multiple, separate facets which can be ranked in a hierarchical fashion. Situation-specific dimensions are located at the base of the model, whereas more situation-stable, general self-concepts are at the apex.

3. Taxonomic - Self-concept is viewed as having many facets which are separate and situation-specific.

4. Compensatory - Self-concept is seen as containing several facets, which are related inversely. For example, a low physical self-concept might be compensated for by a higher academic or social selfconcept.

As the amount of research has increased, and the variety and robustness of instruments used in self-concept research has expanded, an increasing amount of support has been found for multidimensional models of self-concept (see Marsh \& Gouvernet, 1989, for an overview). In particular, Marsh and his colleagues have found a large amount of support for the Hierarchical model (Marsh, Relich, \& Smith, 1983; Marsh, Smith, Barnes \& Butler, 1983; Marsh, Smith, \& Barnes, 1984; Marsh, 1985; Marsh \& Gouvernet, 1989).

Although Marsh and his colleagues based their support for the Hierarchical model from the use of a wide variety of subjects, only 
one of their samples included exceptional youngsters. It is possible that when the self-concepts of exceptional children (gifted, handicapped or learning disabled) are examined, support for one of the other models of self-concept may be found. Rosher and Howell (1978) suggest that the significance of the impact of disability status on Academic self-concept might best be explained as an overcompensation in one field when there is a weakness in another (in Byrne, 1984). Support for the Compensatory model has also been found when the self-concepts of learning disabled, gifted and normal students are compared (Winne, Woodlands, \& Wong, 1982). Finally, additional support for the Compensatory model has come from canonical correlational studies. Marx and Winne found bipolar relations among facets of self-concept, and interpreted the findings to mean that self-concept is composed of compensatory components (in Byrne, 1984). In regards to gifted children, an overall positive self-concept may be obtained by balancing a poor social or physical self-concept with a more positive performance in academic areas. Instrumentation and Methodology Issues

The variety of instrumentation and methodology used in previous studies of self-concept make it problematic to draw general conclusions from the research literature. Most existing measures of self-concept view self-concept in a global manner. In addition, existing measures of self-concept have been widely criticized for their limited norms, lack of reliability, poor validity, and poor theoretical bases (Byrne, 1983; Lakey, cited in Schneider, 1987; Wylie, 1974). Two of the most widely-used measures of self-concept with children are the Coopersmith Scale and the Piers-Harris 
Children's Self-Concept Scale (Schneider, 1987). Harter (1983) reviewed the psychometric properties of these two scales. The Coopersmith inventory showed high test-retest and split-half reliability, but the validity was questioned, since the scale was constructed by reworking a version of an adult self-concept scale. The Piers-Harris Scale was considered an improvement, since it derived its questions from a pool of statements generated by children. However, the Piers-Harris mainly examines global selfconcept. Factor analyses of the Piers-Harris have derived several factors, but they have not been shown to be stable across studies (Jeske, 1985).

Even when examining instruments that are designed to measure multi-dimensional aspects of self-concept, results have not been consistent. Marx and Winne (1978) and Winne, Marx and Taylor (1977) used a multitrait-multimethod study in order to examine the construct interpretations of three self-concept inventories: the Gordon How I See Myself Scale, the Piers-Harris, and the Sears SelfConcept Inventory. They found that although convergent validity was good, divergent validity was not established. In other words, the instruments seemed to be measuring the same construct, but separate domains within the instruments were found to be intercorrelated, thereby denying the existence of multiple dimensions of self-concept. In addition, the researchers found that the response requirements of the instruments affected the resulting construct interpretations. These findings were interpreted by the researchers as showing little evidence for a multidimensional model of self-concept. 
Factor analysis studies of various instruments also provided uneven support for the multidimensionality of self-concept. In general, the studies found evidence for more than one factor, but the derived factors were often difficult to interpret, inconsistent across different samples, or were not clearly related to the scales that were intended (Marsh \& Smith, 1982). However, more recent research (see Marsh \& Gouvernet, 1989, p. 58 for a review) has found clear support for the multidimensionality of self-concept measures. Marsh and Gouvernet postulate that the newer instruments are designed to measure a priori factors that are based on theory, and have used factor analysis to refine and confirm the a priori factors. Two of the more recent self-concept instruments are Marsh's Self-Description Questionnaire and Harter's Perceived Competence Scale For Children. A multitrait-multimethod analysis of these two instruments has demonstrated their convergent and discriminant validity (Marsh \& Gouvernet, 1989).

\section{Sex Differences in Self-Concept}

Also of interest in the study of self-concept is whether sex differences exist, and, if so, in what domains of the construct. Wylie (1968) reviewed the literature, which consisted of primarily American studies and found that girls between the ages of 8 and 13 had more positive self-concepts than boys. In contrast, research which had used Australian subjects showed that boys had higher general self-concepts than girls (Connell, Stroobant, Sinclair, Connell, \& Rogers, 1975; and Smith, 1975, 1978, cited in Marsh, Relich, \& Smith, 1983). However, these studies did not control for the researchers' possible use of different models of self-concept, or 
instrumentation. It is possible that differences may have been lost when a global scale or score was used. Marsh and his colleagues have continued to examine these sex differences in more detail. Their work with pre-adolescent Australian populations has found some reliable findings across sexes specific to particular components of self-concept. Utilizing Marsh's Self-Description Questionnaire, which is based on a multifactor model of self-concept, they found that boys had a higher physical self-concept than girls. Within the academic domain, boys had a higher math self-concept, whereas girls had a higher reading self-concept (Marsh, 1985; Marsh, Barnes, Cairns, \& Tidman, 1984; Marsh, Relich, \& Smith, 1983).

Work has also been done focusing on the educational setting of the subjects and whether an interaction with sex exists. Marsh, Relich, and Smith (1983) found that sex differences in the academic domains previously mentioned were influenced by the whether the subjects attended single-sex classrooms or integrated classes. They found that sex differences were smaller for students attending single-sex classes. Marsh, Relich and Smith suggest that selfconcepts are formed relative to the reference group, so that when the group contains both boys and girls, the differences in self-concept are accentuated in the direction of traditional sexual stereotypes. Conversely, it follows that if the reference group is of the same sex, then differences would not be as large.

The idea that one's reference group influences one's selfperceptions is particularly relevant in the study of exceptional children's self-concepts. Schneider (1987) reports that analyses of sex differences have been reported in very few studies of gifted 
children's self-concepts. No sex differences were found by Karnes and Wherry (1981), but their self-concept measures were rather global. Kelly and Colangelo (1984) found that boys enrolled in a gifted program had higher global self-perceptions than boys enrolled in regular education classes. These regular education boys had higher self-perceptions than special learning needs males. There was no significant effect of class type for girls. However, in this study, the degree of integration that the exceptional children had with their regular classmates was not mentioned. Schneider et al. (1986) examined the self-concepts of gifted and non-gifted children in grades 5, 8 and 10. No sex differences were found at the 5th grade level. At grades 8 and 10, boys displayed higher general and physical self-concepts than girls, regardless of their gifted or nongifted group status. No sex differences were found in the academic or social self-concept domains. Schneider et al. (1989) again examined the self-concepts of gifted children as a function of age, sex, and school program. Gifted children in grade 5 who were integrated with their non-gifted peers for most of the school week had higher academic self-concepts than gifted children who were enrolled in self-contained classes. No sex differences in self-concept were found at grade 5 . In grades 8 and 10 , integrated gifted children had higher academic self-concepts. In addition, boys had higher global and physical self-concepts than girls. No multivariate interaction effects reached significance. Thus, age, sex and school program may be important variables in self-concept research. 


\section{Gifted Children's Self-Concepts}

One group which has been a focus of the self-concept research is the gifted. However, this group has been difficult to define since no universal definitions of giftedness have been adopted. Some researchers, such as Terman, 1925, have defined the gifted in terms of high scores on tests of intelligence, yielding quotients of 130 and above. Other researchers prefer definitions which additionally include areas of high achievement, as in above-average creativity and task commitment (Renzulli, 1978). Congress proposed a general definition used in Public Law (PL) 97-35, the Education Consolidation and Improvement Act, in 1981. According to this definition, the gifted are "children who give evidence of high performance capability in areas such as intellectual, creative, artistic, leadership capacity, or specific academic fields, and who require services or activities not ordinarily provided by the school in order to fully develop such capabilities (in Clark, 1988)." The particular definition of giftedness utilized by the researcher is important to note when considering the literature on this population.

Early studies of gifted childrens' self-concepts found that, generally, gifted children have a higher global self-concept than their non-gifted peers (see Schneider, 1987, for a review). Several researchers have found that when gifted children are compared with non-gifted children, the gifted subjects have higher scores across different measures of self-concept and self-esteem (Lehman \& Erdmins, 1981; Maddux, Schneider, \& Bass, 1982; Ketchman \& Snyder, 1977, in Olszewski-Kubilius, 1989; O'Such, Twyla, \& Havertape, 1979). However, other researchers have reported no 
significant differences (Braken, 1980). The inconsistent findings may be due to several variables. Two such variables are the normative reference group used (if one was utilized) and the instrument's theoretical view of self-concept. Braken (1980) maintains that gifted children's self-concepts are greatly affected by how others perceive and react to special abilities. It is possible that the reference group affects gifted children's self-appraisals, so that when gifted students are homogeneously grouped and compare themselves to other high functioning children, the resulting self-appraisals will be lower than if they compared themselves to a heterogeneous mixture including children of lower abilities.

Addressing the second variable of the instrument's theoretical underpinnings, not all self-concept instruments divide self-concept into specific domains. Therefore, some of the inconsistent findings may be due to early studies utilizing instruments which were constructed viewing self-concept as a global concept rather than divided into distinct domains. It is possible that when discrete portions of the self-concept are examined, differences between gifted and non-gifted children may be found. This has been the case when academic self-concept has been examined. Researchers have found that gifted children have higher academic self-concepts, compared to their social or physical self-concepts (Ross \& Parker, 1980). When gifted children have been compared to their non-gifted peers, it has been found that gifted children possess higher academic selfconcepts than non-gifted children (Kelly \& Colangelo, 1984; Winne, Woodlands, \& Wong, 1982). However, the research does not seem as clear cut when other portions of the self-concept are examined (see 
Schneider, 1987, for a review). Kelly and Colangelo (1984) reported that gifted children also possessed higher social self-concepts than general students, although this finding was not confirmed when the control subjects were learning disabled (Winne, Woodlands, \& Wong, 1982). Thus, some research has proposed that gifted children have higher academic rather than other areas of self-concept, specifically the social self-concept. One may wonder whether children who possess high academic self-concepts are compensating for lower selfperceptions in other areas (Schneider, 1987). These findings may point in the direction that a compensatory process exists in the formulation of self-concept for all children.

Importance of Self-Concept Domains

In studying the self-perceptions of children, very little research has addressed the importance of the specific domains of self-concept to the child. However Harter borrowed from the Jamesian selfconcept model and in her research integrated an importance scale for each of the domains of self-concept. Harter, utilizing the Jamesian model, determined that it is "essential to consider the importance the domains held for the child (James' pretensions) in order to comprehend the relationship that the specific domain profiles bear to the global self-worth" (in Lapsley \& Power, 1988, p. 46). In a study examining the self-concepts of 8 to 15 year-old children, Harter used a separate rating scale for each subject to respond as to how important it was to do well in each domain in order for them to feel good about themselves as a person. She then formulated a discrepancy score by subtracting the importance score from the competence score. Harter found that the results supported James' 
formulation since there was a systematic linear trend between the children's discrepancy scores and the self-worth scores. Children with low self-concept had the highest discrepancy scores, reflecting their view that the importance of the areas of the self-concept exceeded their perceived competence. As self-worth increased, the discrepancy score systematically decreased, so that children with high levels of self-worth had nearly a zero discrepancy score (Harter, 1988). Harter interpreted these findings to mean that a child with low self-worth, or a low general self-concept, can not discount the importance of areas where he or she feels inadequate. Two domains were found to be particularly difficult to discount: behavioral conduct and scholastic competence. Harter points out that these two domains have particularly high normative importance ratings, and are ones that the children felt were most important to their parents. Present Study

The purpose of this study is to address several issues. The first purpose is to explore the global and domain-specific self-concepts of gifted children. As previously demonstrated, research in this area is not abundant. It is possible that gifted children have different selfconcepts than their normal ability peers. To address this possibility, self-concepts of gifted subjects will be compared with those of normal children. Based on Harter's preliminary research, it is hypothesized that gifted children will have higher academic selfconcepts than social or physical self-concepts, since the academic area is one that is difficult to discount and is probably additionally reinforced by teachers, parents and other gifted peers. Non-gifted children will not be expected to have the same self-concept pattern. 
Second, like Harter and James, I believe that it is not enough to measure the self-concepts of children. The relative importance of the particular aspects of self-concept must also be determined. It can be assumed that an individual evaluates him or herself across many dimensions. However, if a particular dimension is considered less important, it may not affect the individual's global self-appraisal to as large an extent. This study will examine the self-reported relative importance of the specific domains. By including a measure of the importance of each domain, it will be interesting to note if different patterns of the importance of particular self-concept domains exist for the gifted and non-gifted children. Lastly, previous literature has indicated that different self-concept profiles may exist for boys versus girls. Thus, in the present study sex differences will be investigated.

\section{Method}

\section{Participants}

Participants were fifth grade students enrolled in the Warwick School District, the second largest school district in Rhode Island. Of the 20 schools comprising the district, eight participated. These schools were chosen because of their high enrollment of students who participated in the district's Advanced Learning Activities Program (ALAP). All schools contacted agreed to participate in the research. All fifth grade classrooms at each cooperating school participated, yielding a total of eighteen classrooms from which participants were drawn. 
The gifted and talented program in the Warwick School District is entitled the Advanced Learning Activities Program (ALAP).

Representatives from the program contact teachers at the end of the first and second grades for orientation regarding the selection procedure of children to enter the program in grade three. Identification occurs through a combination of teacher recommendation, standardized test data, and parent inventory. Participating students are bussed to a central school for a half day of activities once every other week. Instruction consists of a combination of small and large group activities which center around a common theme. Individual work relating to the unit of study is also assigned. Program goals include acquiring of advanced skills in critical thinking and cognitive synthesis, developing interpersonal skills, enhancing self-concept, and producing high-quality products. ALAP students are grouped by age. Fifth and sixth graders from the same school participate in activities together. District-wide, the total number of fifth grade students participating in the program was 60.

A total of 288 fifth graders participated in the study. Of this number, 34 were ALAP participants. The ALAP group's mean age was 10.5 years, with a range from 10 to 11 years of age. The regular education group's mean age was 10.7 years, with a range from 9 to 12 years of age. Sample sizes differed slightly for each analysis since incomplete profiles were dropped from the analysis. 


\section{Instruments}

Each participant completed a packet of four instruments. Instructions for each of the instruments were read aloud to the participants at the start of the task. Items on the longer checklists were also read aloud and the child was asked to follow at the examiner's pace.

The first instrument administered was a variation of Kuhn and McPartland's "Who Am I?" task (1954). This instrument requires the child to self-generate ten descriptions of him or herself by responding to the question, "Who Am I?" Kuhn and McPartland's version of the test was scored by coding the proportion of selfderogating statements and scoring for strength of self-derogation or self-positivity. Poor convergent validity with three additional selfconcept measures was found by Spitzer et al. (1966). Data on discriminative and predictive validity was not reported. This type of scoring did not suite the purposes of this project, and another method was used. Validity and reliability data of this scoring system is not known. However, the instrument appeared to have face validity and followed from the purpose of the study, and therefore was included. This measure was chosen to be administered first because of its open-ended approach. It was believed that the participants would therefore have no preconceptions of reporting particular areas of self-concept.

The second instrument was developed for the purposes of the study. The "Importance Scale" consisted of ten statements which participants were asked to respond to on a 5-point Likert-type scale. Responses ranged from "Not At All" (1) to "Very" (5) important. Each 
question corresponded to each of the seven specific self-concept domains of Marsh, Parker and Smith's (1981) Self Description Questionnaire (SDQ), as well as to three larger self-concept domains (Academic, Physical and Social). The "Importance Scale" was administered second because it covered similar material to the SDQ, but in a more abstract manner.

The third instrument administered was Marsh's Self Description Questionnaire (Marsh, Parker, and Smith, 1981), an eightscale, 72-item instrument intended to measure seven aspects of the self-concepts of children between the ages of seven and thirteen, as well as a general global self-concept measure. Each item was responded to on a five-point Likert-type scale from "false" (1) to "true" (5). The areas of the SDQ include measures of Academic (Reading, Mathematics, and General-School subjects), Physical (Physical Abilities/sports and Physical Appearance), and Social (Peer Relations and Parent Relations) self-concepts. A measure of global self-concept is also available, but was not focused on in this study. Wylie (1989) reviewed the SDQ and reported internal consistency alpha coefficients between .82 and .93 . Test-retest coefficients were moderate to high values, depending on the test-retest interval. Construct validity assessed through factor analysis yielded seven factors plus a global self-concept factor, as was expected by a priori analyses (Wylie, 1989). The SDQ has since been revised (1988) and now incorporates slightly different items which correspond to the same eight factors of self-concept.

The final measure was a "Pie Chart" of self-concept which was constructed for the purposes of the study. This task required the 
participant to fill in the areas of Physical, Social and Academic selfconcept in order to describe how important each of these areas is in proportion to his or her overall self-concept. This measure was designed to be an alternative measure of the importance of the selfconcept areas, as well as a simple and interesting task to enhance the participant's motivation.

\section{Procedures}

Classroom teachers gave all fifth grade students at the participating schools a passive consent form to be read by their parents. Parents were asked to return the signed form only if they wished their child not to participate in the study (see Appendix A for a copy of the consent letter). Non-participating children were provided with alternate activities by their classroom teacher.

The examiner administered the inventories to all participants in their regular education classrooms. Participants were asked to read along with the examiner and complete the items at that rate. Instruments were administered in the aforementioned order: the Who Am I?, the Importance Scale, the Self-Description Questionnaire, and the Pie Chart (see Appendix B). Additional time was provided for participants who needed to finish completing parts of the inventories. Completion of the inventories took between 45-60 minutes. Participants indicated their grade, school, age, teacher and sex in blanks provided on the cover page of the SDQ. Participants were also asked to circle their school activities, such as band, art, basketball, drama and ALAP. Confirmation of ALAP status was provided by the classroom teacher who was asked to collect all 
completed inventories and make a check on those belonging to ALAP participants.

\section{Results}

\section{The Who Am I? Scale}

The Who Am I? scale allows the participant to self-generate his or her own categories of self-concept. An undergraduate assistant scored the instrument by determining whether the students described themselves according to physical, social and academic selfconcept domains. The assistant was given the Physical, Social and Academic domain descriptions used in the instructions of the Pie Chart. Any sentences which did not appear to fit exclusively in one domain were placed in an "Other" category. A total of 37 protocols from the ALAP group and 251 protocols from the Regular Education group were analyzed. The examiner independently rescored a random sample of 50 profiles to provide an inter-rater reliability coefficient. Reliability coefficients were $r=.77$ for the Academic domain, $r=.78$ for the Other category, $r=.86$ for the Physical domain, and $r=.89$ for the Social domain.

Frequencies of the number of sentences included in each of the four categories were calculated for the ALAP and the regular education groups. The number of sentences in each self-concept domain and its corresponding percentage of the total number of 10 sentences was calculated for the ALAP and regular education groups. This information is provided in Table 1. For both groups, the Academic category contained the fewest number of sentences, and the Other category contained the most. 
Table 1

Percentage of the Total Number of Sentences For Each Category of the Who Am I Instrument

Category of Self-Concept

\begin{tabular}{|c|c|c|c|c|}
\hline & Physical & Social & Academic & Other \\
\hline ALA & 24 & 19 & 7 & 50 \\
\hline Regular Ed. $(n=251)$ & 26 & 28 & 8 & 38 \\
\hline
\end{tabular}

The ALAP group's ordering of the categories from highest to lowest was Academic, Social, Physical, and Other. The regular education group's ordering was Academic, Physical, Social and Other.

To determine whether the ALAP and regular education groups were using the self-concept domains in a similar manner, the Kolmogorov-Smirnov 2-Sample Test was calculated. For the Physical domain, $Z=1.004$, with a 2-tailed $P>.05$. For the Social domain, $\mathrm{Z}=1.185, \mathrm{P}>.05$. For the Academic domain, $\mathrm{Z}=.382, \mathrm{P}>.05$. For the Other category, $Z=1.295, P>.05$. Thus, no significant differences were found between the ALAP and regular education participants in terms of their use of the categories.

The Kolmogorov-Smirnov 2-Sample test was also calculated to determine whether there were significant differences in the way males and females used each of the four categories. For the Physical category, $Z=1.601, p<.05$. For the Social category, $Z=.430, p>.05$. For the Academic category, $Z=.745, p>.05$. For the Other category, $Z=.858$, p>.05. Thus, significant differences between males and females were found only in the use of the Physical category.

To examine the amount of agreement between the ALAP and regular education groups in the ranking of the four categories, 
Kendall's Coefficient of Concordance (Kendall's W) was calculated. For the entire sample, $W(3)=.3289$, Chi-Square $=284.1329, p<.05$. For the ALAP sample, $\mathrm{W}(3)=.4343$, Chi-Square $=48.2087, \mathrm{p}<.05$. For regular education participants, $W(3)=.3183$, Chi-Square $=239.6876, p<.05$.

Kendall's W was also calculated to determine the degree of agreement in the self-concept rankings across the two sexes. For males, $\mathrm{W}(3)=.3360$, Chi-Square $=144.1323, \mathrm{p}<.05$. For females, $\mathrm{W}(3)=.3264$, Chi-Square $=131.2152, \mathrm{p}<.05$. Both the male and female samples demonstrated a similar degree of agreement in their rankings of the self-concept domains.

\section{The Importance Scale}

A total of 275 complete profiles were analyzed. This total was comprised of 15 ALAP males, 19 ALAP females, 128 regular education males, and 113 regular education females.

A Principle Components Analysis of the ten statements comprising the Importance Scale was performed to assess the underlying structure of this measure. Three factors emerged, which accounted for 61.9 percent of the variance. Factor 1 corresponded to Academic self-concept, Factor 2 to Physical self-concept, and Factor 3 to Social self-concept. Table 2 shows the three factor structure and the factor loadings of each item. 
Table 2

Importance Scale Factors and Factor Loadings of Individual Items

Factor 1 - Academic Self-Concept

1. It is important to me to do well in Reading.

Factor Loading

8. It is important to me to do well in Math.

8. It is important to me to do well in Math. .81

5. It is important to me to do well in all my school subjects. $\quad .79$

7. It is important to me to be a good student.

Factor 2 - Physical Self-Concept

9. It is important to me to be good-looking.

3. It is important to me to be healthy, sporty, and good-looking.

6. It is important to me to do well in sports.

\section{Factor 3 - Social Self-Concept}

10. It is important to me to be liked and get along well with people.

4. It is important to me to have good friends and be liked by friends.

2. It is important to me to get along well with my parents. 
Three sub-scale means were calculated by combining the responses to the sentences that loaded on each of the three factors and dividing by the number of items. The resulting Physical scale contained three items, the Social scale three items, and the Academic scale four items. A 2 (sex) by 2 (ALAP grouping) by 3 (self-concept domain) Repeated Measures Analysis of Variance was conducted on the mean scores of each of the domains. Table 3 shows the source table for this analysis.

Table 3

Source Table For the Repeated Measures ANOVA For the Importance Scale

\begin{tabular}{lrrrr} 
Source & $\frac{\mathrm{df}}{1}$ & \multicolumn{1}{l}{ SS } & \multicolumn{1}{l}{ MS } & \multicolumn{1}{l}{ F } \\
Sex & 1 & .13 & .13 & .68 \\
ALAP & 1 & .00 & .00 & .99 \\
Sex X ALAP & 1 & .08 & .08 & .75 \\
Error-Between & 271 & 206.93 & .76 & \\
& & & & \\
Subscale & 2 & 42.07 & 21.03 & $51.74^{*}$ \\
Sex X Subscale & 2 & 2.80 & 1.40 & $3.45^{*}$ \\
ALAP X Subscale & 2 & .50 & .25 & .61 \\
Sex X ALAP X Subscale & 2 & .18 & .09 & .23 \\
Error-Within & 542 & 220.36 & .41 &
\end{tabular}

${ }^{*} \mathrm{p}<.05$

A significant main effect for the subscales was found, $F(2$, $542)=51.74, p<.05$, with the Social domain being described as most important $(M=4.61)$, followed by the Academic domain $(M=4.41)$, and the Physical domain described as least important $(M=3.87)$. To determine whether each of the means differed significantly from each other, follow-up Analyses of Variance were conducted with the 
appropriate error term calculated for each comparison. All three comparisons yielded significant results at the $\mathrm{p}<.05$ level.

A significant interaction between sex and domain was also found: $F(2,542)=3.45, p<.05$. The means for this interaction are shown in Table 4. Simple effects tests comparing males and females found a significant difference on only the Physical domain, whereby females viewed the Physical domain as less important than the males. Additional simple effects tests comparing the three domains within each sex group found that the Physical, Social, and Academic domains differed significantly from each other for both the male and female participants.

Table 4

Mean Score and Standard Deviation By Sex On the Three Domains of the Importance Scale

$$
\frac{\text { Males }}{\text { Mean }}(n=143) \text { SD } \quad \frac{\text { Females }}{\text { Mean }}(n=132)
$$

$\begin{array}{lllll}\text { Physical } & 3.99 & .94 & 3.72 & .85 \\ \text { Social } & 4.58 & .61 & 4.65 & .50 \\ \text { Academic } & 4.34 & .71 & 4.48 & .63\end{array}$

Note: Items were scored from 1 (not important) to 5 (very important).

\section{The Self-Description Questionnaire}

The current, published version of the SDQ is a revised form of the instrument used in this study. For the revision, negatively worded items were removed, and the wording of some of the 
remaining items was slightly altered. To address whether the revised and earlier versions of the SDQ had a similar factor structure, a Principle Components Analysis with the negative items removed was performed on the earlier version of the instrument used in this study. This analysis yielded eight factors, which accounted for 75.1 percent of the total variance. These eight factors compared favorably to the eight factors identified by the revised SDQ.

The 72 items comprising the SDQ were grouped according to the instructions in the manual of the revised form of the instrument. Nine scales were formulated: seven subscales (Physical Abilities, Physical Appearance, Peer Relations, Parent Relations, Reading, Mathematics, General-School), a General-Self scale, and a scale comprised of the negatively worded items. The seven subscales were then grouped to create the three larger Physical Total, Social Total and Academic Total subscales. Physical Abilities and Physical Appearance were combined to create the Physical Total variable. Peer Relations and Parent Relations were combined to formulate the Social Total variable. The Reading and Mathematics subscales were combined with the General-School subscale to create an Academic Total variable. Since the General-Self subscale was not utilized in the scoring of the revised SDQ, it was left as a separate scale. The ninth scale of the negatively worded items was not utilized. Table 5 lists the scales and the particular items comprising each subscale. 


\section{Table 5}

\section{SDO Subscales and Items}

Physical Abilities Scale:

3. I can run fast.

10. I like to run and play hard.

24. I enjoy sports and games.

32. I have good muscles.

40. I am good at sports.

48. I can run a long way without stopping.

56. I am a good athlete.

64. I am good at throwing a ball.

Physical Appearance Scale:

1. I am good looking.

8. I like the way I look.

15. I have a pleasant looking face.

22. I am a nice looking person.

38. Other kids think I am good looking.

46. I have a good looking body.

54. I am better looking than most of my friends.

62. I have nice looking features like nose and eyes and hair.

Peer Relations Scale:

7. I have a lot of friends.

14. I make friends easily.

28. I get along with other kids easily.

36. I am easy to like.

44. Other kids want me to be their friend.

52. I have more friends than most other kids.

60. I am popular with other kids of my own age.

68. Most other kids like me.

\section{Parent Relations Scale:}

5. My parents understand me.

19. I like my parents.

26. My parents like me.

34. If I have children of my own I want to bring them up like my parents raised me.

42. My parents and I spend a lot of time together.

50. My parents are easy to talk to.

58. I get along well with my parents.

66. My parents and I have a lot of fun together. 


\section{Reading Scale:}

4. I get good grades in reading.

11. I like reading.

18. I'm good at reading.

25. I am interested in reading.

41. I enjoy doing work in reading.

49. Work in reading is easy for me.

57. I look forward to reading.

71. I learn things quickly in reading.

\section{Mathematics Scale:}

13. Work in mathematics is easy for me.

20. I look forward to mathematics.

27. I get good grades in mathematics.

35. I am interested in mathematics.

43. I learn things quickly in mathematics.

51. I like mathematics.

59. I'm good at mathematics.

67. I enjoy doing work in mathematics.

\section{General-School Scale:}

2. I'm good at all school subjects.

9. I enjoy doing work in all school subjects.

16. I get good grades in all school subjects.

31. I learn things quickly in all school subjects.

39. I am interested in all school subjects.

55. I look forward to all school subjects.

63. Work in all school subjects is easy for me.

70. I like all school subjects.

\section{General-Self Scale:}

29. I do lots of important things.

45. In general I like being the way I am.

53. Overall I have a lot to be proud of.

69. Overall I am good at the things I like to do.

\section{Negatively Worded Items:}

6. I hate mathematics.

12. My parents are usually unhappy or disappointed with what I do.

17. I hate sports and games.

21. Most kids have more friends than I do.

23. I hate all school subjects.

30. I am ugly.

33. I am dumb at reading.

37. Overall I am no good.

47. I am dumb in all school subjects.

61. I hate myself.

65. I hate reading.

72. I am dumb at mathematics. 
The SDQ was analyzed by three separate Analyses of Variance. The first analysis consisted of a 2 (sex) by 2 (ALAP grouping) factorial Analysis of Variance on the General-Self variable. A total of 271 completed protocols were analyzed, consisting of 14 ALAP males, 19 ALAP females, 126 regular education males and 112 regular education females. The source table for this analysis is shown in Table 6.

Table 6

Source Table For the ANOVA of the General-Self Variable

$\underline{\text { Source }}$

Sex

ALAP

Sex X ALAP

Error

${ }^{*} \mathrm{p}<.05$

\begin{tabular}{rrc}
\multicolumn{1}{c}{ SS } & \multicolumn{1}{c}{ MS } & F \\
73.49 & 73.49 & $9.89^{*}$ \\
1.27 & 1.27 & .17 \\
10.25 & 10.25 & 1.42 \\
983.42 & 7.43 &
\end{tabular}

7.43
.17

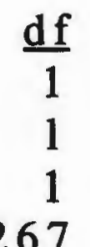

1

1 267

A significant main effect for sex was found, $F(1,267)=9.893$, $\mathrm{p}<.05$, with males reporting higher general self-concepts $(M=4.30)$ than females $(M=4.04)$.

The second SDQ analysis was a 2 (sex) by 2 (ALAP grouping) by 3 (self-concept domain) Repeated Measures Analysis of Variance on the mean scores of the three composite domains. A total of 232 completed profiles were analyzed, comprised of 13 ALAP males, 17 ALAP females, 106 regular education males, and 96 regular education females. The source table for this analysis is shown in Table 7. 
Table 7

Source Table For the Repeated Measures ANOVA For the Three Total Domains of the SDQ

\begin{tabular}{|c|c|c|c|c|}
\hline Source & $\underline{\mathrm{df}}$ & $\underline{\text { SS }}$ & $\underline{\mathrm{MS}}$ & $\underline{F}$ \\
\hline Sex & 1 & 5.79 & 5.79 & $5.55 *$ \\
\hline ALAP & 1 & .00 & .00 & .00 \\
\hline Sex.X.Alap & 1 & 1.67 & 1.67 & 1.6 \\
\hline Error-Between & 228 & 237.84 & 1.04 & \\
\hline Subscale & 2 & 1.20 & .60 & 2.03 \\
\hline Sex X Subscale & 2 & 4.16 & 2.08 & $7.03 *$ \\
\hline ALAP X Subscale & 2 & 6.33 & 3.17 & $10.69 *$ \\
\hline Sex X ALAP X Subscale & 2 & .21 & .10 & .35 \\
\hline Error-Within & 456 & 135.10 & .30 & \\
\hline
\end{tabular}

A significant main effect for sex was found, $F(1,228)=5.55$, $\mathrm{p}<.05$, with males reporting a higher composite of the three domains of self-concept $(M=3.83)$ than females $(M=3.66)$. In addition, a significant interaction of sex and subscale was found, $F(2,456)=7.03$, p<.05. Simple effects tests indicated that males rated the Physical and Social domains similarly and significantly higher than the Academic domain. Females rated the Social domain significantly higher than both the Academic and Physical domains, which did not differ significantly from each other. The means for the two groups are shown in Table 8. Simple Effects tests were also performed on the differences between male and female respondents across the three domains. A significant difference between males and females was found only on the Physical domain. 
Table 8

Mean Score and Standard Deviation By Sex for the Three Total

Subscales of the SDQ

\begin{tabular}{|c|c|c|c|c|}
\hline \multirow[b]{3}{*}{ Physical } & \multicolumn{2}{|c|}{ Males $(n=119)$} & \multicolumn{2}{|c|}{ Females $(n=113)$} \\
\hline & Mean & $\mathrm{SD}$ & Mean & SD \\
\hline & 4.02 & .71 & 3.50 & .80 \\
\hline Social & 4.00 & .63 & 3.89 & .73 \\
\hline Academic & 3.47 & .84 & 3.60 & .74 \\
\hline
\end{tabular}

Note: Each item was scored on a scale from 1 (false) to 5 (true).

A significant ALAP grouping by subscale interaction was also found, $F(2,456)=10.69$, p<.05. Simple effects tests indicated that children participating in the ALAP program did not report significant differences among the three domains. Regular education children reported the Social domain as highest, with Physical self-concept as secondary, and Academic self-concept as lowest; each of these domains were found to be significantly different from each other. The means are shown in Table 9. Simple Effects tests examining the differences between the academic groupings for each of the three domains were also performed. The results indicated that ALAP and regular education participants differed significantly in their ratings of the Social and Academic domains only. 
Table 9

Mean Score and Standard Deviation By Academic Group for the Three Total Subscales of the SDO

\begin{tabular}{|c|c|c|c|c|}
\hline \multirow[b]{3}{*}{ Physical } & \multicolumn{2}{|c|}{$\underline{\operatorname{ALAP}}(\mathrm{n}=32)$} & \multicolumn{2}{|c|}{ Regular Education $(n=207)$} \\
\hline & Mean & $\mathrm{SD}$ & Mean & SD \\
\hline & 3.69 & .66 & 3.78 & .82 \\
\hline Social & 3.64 & .73 & 3.99 & .66 \\
\hline Academic & 3.85 & .72 & 3.40 & .79 \\
\hline
\end{tabular}

Note: Each item was scored on a scale from 1 (false) to 5 (true).

The third analysis on the SDQ was a 2 (sex) by 2 (ALAP grouping) by 7 (subscale) Repeated Measures Analysis of Variance on the seven self-concept subscales. This analysis was conducted to determine if their were differing patterns between the groups on the seven more specific domains. A total of 232 completed protocols were analyzed, comprised of 13 ALAP males, 17 ALAP females, 106 regular education males, and 96 regular education females. The source table for this analysis is shown in Table 10.

As indicated in the previous analysis, a significant main effect for sex was found, $F(1,228)=4.07, p<.05$, with males demonstrating higher self-concepts $(M=3.78)$ than females $(M=3.66)$. A significant main effect for subscale was also found, $F(6,1368)=13.53, p<.05$. The sample rated itself highest in the Parent Relations $(M=4.09)$ and Physical Abilities $(M=4.05)$ domains, and lowest in the GeneralSchool subjects domain $(M=3.25)$. The means and standard deviations of the seven domains are shown in Table 11. 
Table 10

Source Table For the Repeated Measures ANOVA for the Seven Domains of the SDQ

Source

Sex

ALAP

Sex X ALAP

Error-Between

Subscale

Sex X Subscale

ALAP X Subscale

Sex X ALAP X Subscale

Error-Within

${ }^{*} \mathrm{p}<.05$

\begin{tabular}{rrrc}
$\frac{\mathrm{df}}{1}$ & \multicolumn{1}{c}{$\underline{\mathrm{SS}}$} & \multicolumn{1}{c}{$\mathrm{MS}$} & \multicolumn{1}{c}{$\underline{10.11}$} \\
1 & 10.11 & $.07^{*}$ \\
1 & 4.20 & .47 & .19 \\
228 & 565.96 & 2.48 & 1.69 \\
& & & \\
6 & 42.86 & 7.14 & $13.53^{*}$ \\
6 & 16.42 & 2.74 & $5.19^{*}$ \\
6 & 19.81 & 3.30 & $6.25^{*}$ \\
6 & .81 & .14 & .26 \\
1368 & 722.14 & .53 &
\end{tabular}


Table 11

Subscale Means for the Seven SDQ Areas

Subscale

Physical Abilities

$\underline{\text { Mean }}$

4.05

$\underline{\mathrm{SD}}$

Physical Appearance

3.49

.99

Peer Relations

3.80

Parent Relations

4.09

Reading

3.68

.89

Mathematics

General-School

Note: Each item was scored on a scale from 1 (false) to 5 (true).

In addition, a significant Sex by Subscale interaction was found, $F(6,1368)=5.19, p<.05$. The two groups appeared to be rating their specific abilities quite differently. Females rated each self-concept area lower than males, except for the Reading and General-School domains. Simple effects tests were performed to determine which specific areas differed significantly from the others. Significant differences between males and females were found in the Physical Abilities, Physical Appearance, Peer Relations, Reading, and GeneralSchool areas. Figure 1 shows a graph of the seven domain scores for the two groups. Simple effects tests for domain differences within each sex group were also performed. Overall, these results mirror those found in the earlier three domain analysis. Table 12 shows the pairwise differences for males, and Table 13 shows the pairwise differences for females. 
Figure 1. Mean Scores on the Seven SDQ Domains By Sex

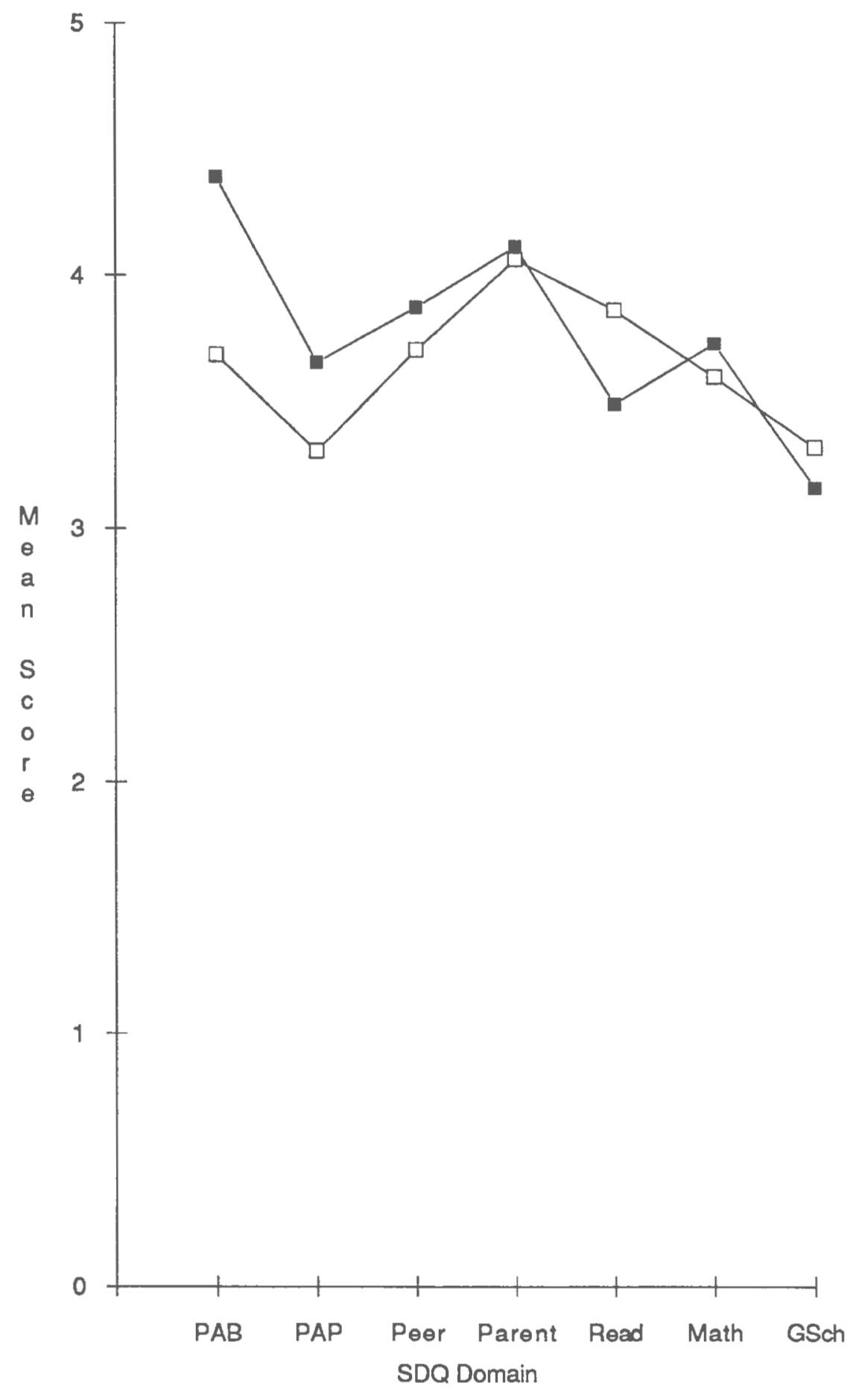


Table 12

Male Sample Pairwise Mean Differences

$\underline{\text { GSch Read }} \underline{\text { PAP }}$ Math $\underline{\text { Peer }} \underline{\text { Parent }} \underline{\text { PAB }}$

$\begin{array}{lllllll}\text { GSch } & .33 * & .49 * & .57 * & .71 * & .95 * & 1.22 * \\ \text { Read } & - & .16 & .24 * & .33 * & .62 * & .89 * \\ \text { PAP } & & - & .09 & .22 * & .46 * & .73 * \\ \text { Math } & & & - & .14 & .38 * & .65 * \\ \text { Peer } & & & - & .24 * & .51 * \\ \text { Parent } & & & & - & .27 * \\ \text { PAB } & & & & & -\end{array}$

Table 13

Female Sample Pairwise Mean Differences

$\underline{\text { PAP }} \underline{\text { GSch }} \underline{\text { Math }} \underline{\text { PAB }}$ Peer $\underline{\text { Read }}$ Parent

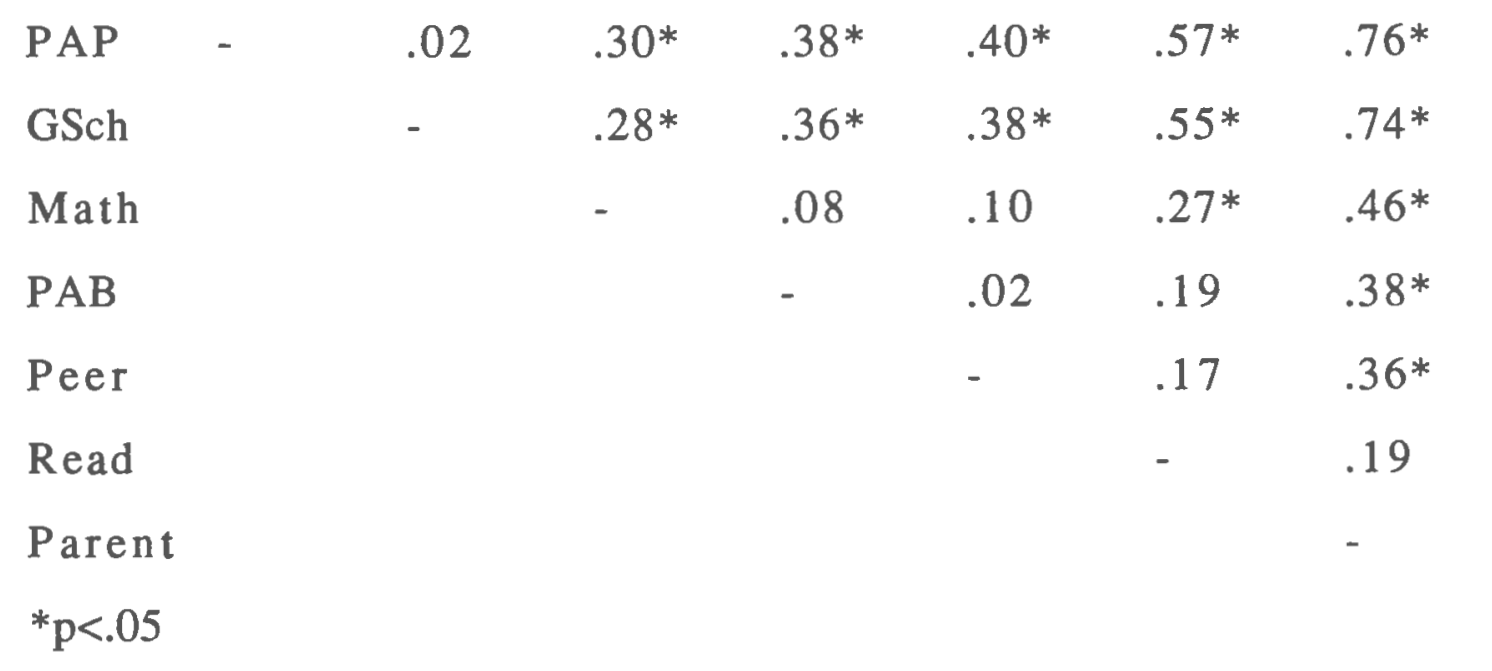


A significant ALAP grouping by Subscale interaction was also found, $F(6,1368)=6.25, p<.05$. ALAP participants rated themselves as lower across the Physical and Social self-concept areas, but higher on the three academic domains. Simple effects tests were calculated to determine on which variables the two groups significantly differed. ALAP and regular education participants significantly differed in their ratings of their Peer Relations, Reading abilities and General-School abilities. A graph of the two group's scores for each specific area is shown in Figure 2. Simple effects tests for domain differences within each academic grouping were also performed. Significant differences in the ratings of the seven domains were found within both the ALAP and Regular Education groups. The ALAP group rated the Reading domain the highest and the Physical Appearance domain the lowest. The Regular Education group rated the Parent relationship domain the highest and the General-School domain the lowest. Table 14 shows the pairwise differences for the ALAP group and Table 15 shows the pairwise differences for the Regular Education group. 
Figure 2. Mean Scores on the Seven SDQ Domains By Academic Grouping

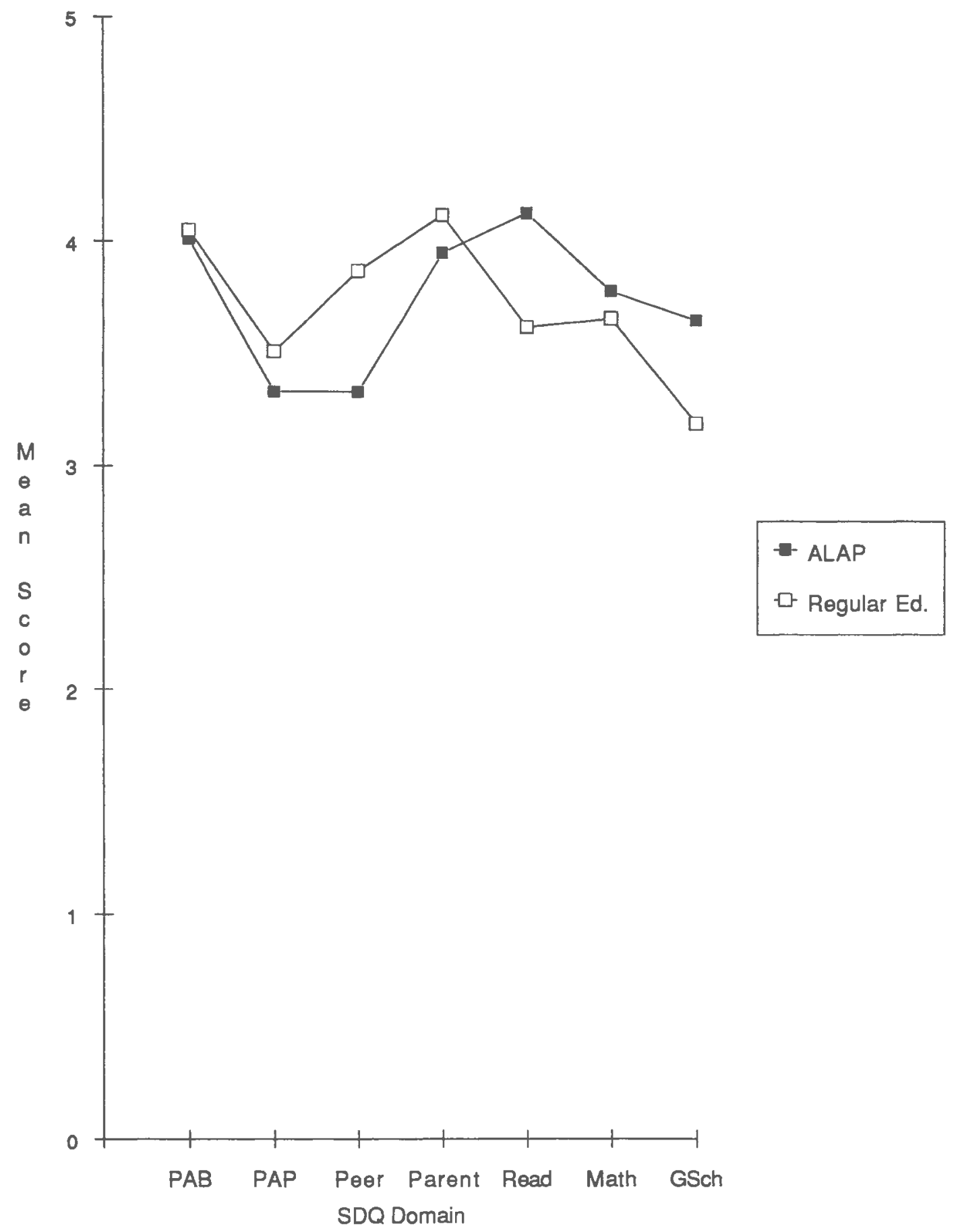


Table 14

ALAP Sample Pairwise Mean Differences

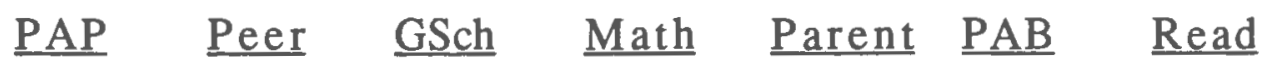

PAP - $\quad \begin{array}{lllllll}.01 & .28 & .45^{*} & .57 * & .67^{*} & .76 *\end{array}$

Peer

.27

$.44 *$

$.56 *$

$.64 * \quad .75 *$

GSch

.17

$.29 *$

$.37 * \quad .48 *$

Math

.12

$.20 *$

$.31 *$

Parent

$.08 \quad .19 *$

PAB

$\begin{array}{ll}- & .11\end{array}$

Read

$* \mathrm{p}<.05$

Table 15

Regular Education Sample Pairwise Mean Differences

GSch $\underline{\text { PAP }} \underline{\text { Read }}$ Math Peer $\underline{\text { PAB }}$ Parent

GSch - $\quad .33 * \quad .44 * \quad .46 * \quad .69 * \quad .87 * \quad .94 *$

PAP

.11

.13

$.36 *$

$54 *$

$.61^{*}$

Read

.02

$.25^{*}$

$.43 *$

$.50 *$

Math

$.23 *$

$.41 * \quad .48 *$

Peer

$.18^{*} \quad .25 *$

PAB

.07

Parent

${ }^{*} \mathrm{p}<.05$ 


\section{The Pie Chart}

Participants were asked to complete the instrument by designating and labeling slices of the pie chart in terms of the importance of each of the three self-concept domains to them. Complete protocols were scored by ranking the pie slices from largest (1) to smallest (3). It was possible to achieve tied ranks. In terms of Academic status, a total of 37 ALAP and 246 Regular Education protocols were analyzed. In terms of gender, a total of 140 male and 132 female protocols were analyzed. Each of the self-concept domains were correlated with the others. The correlation between the Social and Physical domains was $r=-.39$; for the Academic and Physical domain, $\mathrm{r}=-.62$; for the Academic and Social domains, $\mathrm{r}=-.47$. Inter-rater reliability coefficients were calculated by having the faculty advisor rescore the random sample of fifty protocols. Reliability coefficients were $r=.93$ for the Physical domain, $r=.85$ for the Social domain, and $\mathrm{r}=.94$ for the Academic domain.

To examine whether the samples ranked the self-concept descriptions in a similar fashion, the Kolmogorov-Smirnov 2-Sample Test was conducted. In comparing the ALAP to regular education groups on the Physical self-concept ranking, $Z=1.525, p<.05$. For the Social self-concept ranking, $\mathrm{Z}=.802, \mathrm{p}>.05$. For the Academic selfconcept ranking, $Z=1.708, p<.05$. Thus, there were significant differences in the manner which the ALAP and regular education groups are ranking the Physical and Academic domains.

The Kolmogorov-Smirnov 2-Sample test was also conducted to determine if there were differences in the way males and females ranked the self-concept domains. For the Physical domain, $Z=2.799$, 
$\mathrm{p}<.05$. For the Social domain, $\mathrm{Z}=1.943, \mathrm{p}<.05$. For the Academic domain, $\mathrm{Z}=1.547, \mathrm{p}<.05$. Thus, males and females significantly differed in their rankings of each of the three self-concept domains.

To determine whether groups showed consensus in their rankings of the importance of the three self-concept domains, the Kendall Coefficient of Concordance was calculated. For the entire sample, $\mathrm{W}(2)=.06$, Chi-Square $=32.57, \mathrm{p}<.05$. To determine whether there were differences within the ALAP and regular education groups in their agreement of the rank orderings, Kendall's W was calculated with ALAP status as the grouping variable. For the ALAP sample, $W(2)=.1014$, Chi-Square $=7.50, p<.05$. For the regular education sample, $\mathrm{W}(2)=.08$, Chi-Square $=37.59, \mathrm{p}<.05$. Low agreement was found within each of the groups.

Kendall's W was also calculated for the male and female groups. For males, $\mathrm{W}(2)=.24$, Chi-Square $=66.57, \mathrm{p}<.05$. For females, $\mathrm{W}(2)=.01$, Chi-Square $=.63, p>.05$. The males showed a low amount of agreement in their rankings of the domains.

The mean ranks of the three pie chart domains for each of the groups were plotted. Different patterns existed for the ALAP group, whose ranking of the areas from most important to least important was Academic, Physical, and Social, and the regular education students whose ranking of the self-concept domains was Physical, Social, and Academic. Figure 3 shows the rankings of the pie chart areas by ALAP grouping.

Differences also existed in the rankings of the areas for males and females. Males ranked the Physical domain as most important. Social and Academic self-concept was less important. Females 
Figure 3. Mean Ranks for the Three Domains of the Pie Chart By Academic Grouping

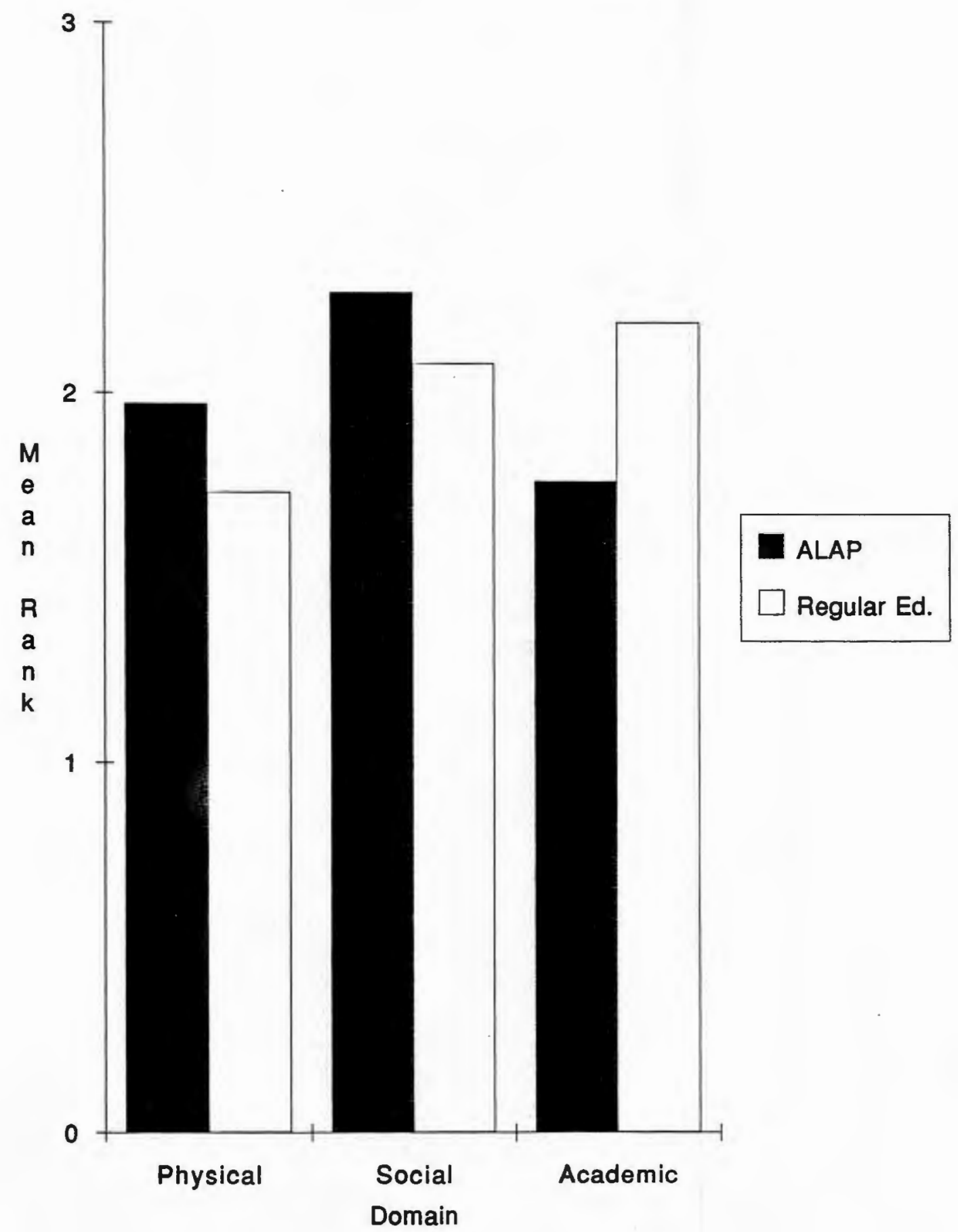


ranked all three domains as similarly important. These rankings are shown in Figure 4. 
Figure 4. Mean Ranks for the Three Domains of the Pie Chart By Sex

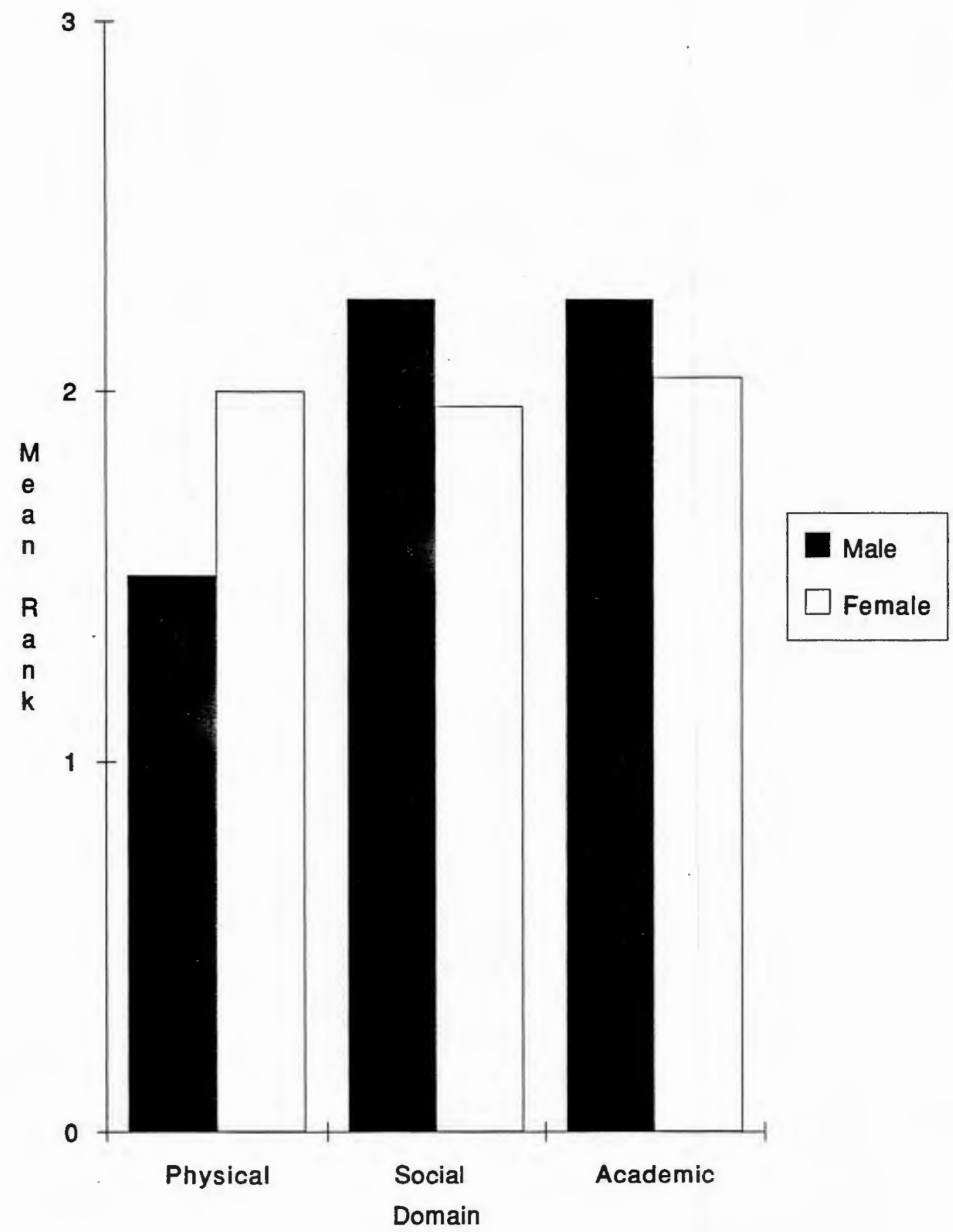




\section{Discussion}

\section{Appraisal of General and Specific Self-Concepts}

Significant differences were found in the participants' ratings of their global and domain-specific self-concepts. Sex differences were found on the global self-concept measure, with males reporting higher overall self-concepts than the females. This finding is in concordance with Marsh's research with Australian participants (Marsh, Relich, \& Smith, 1983).

Significant differences were also found in the appraisal of three domains of self-concept. The participants were able to differentiate seven domains of self-concept. These areas were also rated differently, with the fifth-grade sample rating their relations with their parents and their physical abilities the highest. The overall sample rated their abilities in general school subjects the lowest.

Group differences were found in the ratings of self-concept domains. Significant Academic grouping by Domain interactions were found on both the three and seven domain analyses. As with the research of Kelly and Colangelo (1984), and Winne, Woodlands and Wong (1982), the ALAP participants demonstrated academic self-concepts that were significantly higher than that of their normal-ability peers. Results from the Who Am I? scale indicated that the ALAP and regular education groups differed in the of number of sentences they utilized in each self-concept category. However, there were no significant differences between the two groups in the ranking of these categories.

When differences between the self-concept domains within the regular education and ALAP groups were examined, the results 
become more complex. Significant differences were found in the ratings of the three domains by the regular education sample. The Social domain was rated the highest, followed by the Physical domain, and finally the Academic domain. However, the ALAP group did not perceive differences between the three self-concept areas.

Clearer sex differences were found in the ratings of selfconcept. As with the general self-perception rating, males were found to have a higher composite self-concept score. Differences between males and females were also found of the ratings of the specific self-concept domains. Differences between the two groups were found primarily on the Physical domain, with males ranking the area the highest, and females, the lowest. In the seven-domain analyses, females reported lower abilities in all areas except Reading and General School subjects. This finding supports earlier research by Marsh, who found that females consistently reported higher Reading self-concepts than males.

Significant differences between ratings of the self-concept domains were also found within the male and female samples. On the three domain analysis, males rated the Physical and Social domains significantly higher than the Academic domain. Females rated the Social domain the highest, whereas the Physical and Academic domains were rated significantly lower. On the seven domain analysis, many significant differences were found within the groups. However, as with earlier research findings, females rated their reading abilities significantly higher than their math abilities. In addition, males rated their math skills significantly higher than their reading skills. 


\section{Differences in the Importance of Self-Concept}

Significant differences were found in the overall rating by the entire sample of the importance of the three self-concept domains. The Social area was rated as most important, the Academic area of second importance, and the Physical area as least important.

Group differences were also found in the importance of the domains. As shown by the results of the Pie Chart Instrument, the ALAP group differed from their regular-education counterparts in their ratings of the importance of the Academic and Physical domains. For the ALAP group, doing well in school and being a good student were most important. Their normal-ability peers rated being attractive and showing physical coordination as most important. This pattern must be examined with caution, however, as a low level of agreement was found within the groups in their rankings of the importance of the domains.

As with the appraisal of the self-concept areas, clearer sex differences were found in the importance of the self-concept domains. Males rated the Physical domain as significantly higher in importance than their female peers. Males also showed a higher level of concordance in their rankings on the Pie Chart Instrument. Females rated the Academic, Social and Physical domains of similar importance.

\section{Implications}

The previous results offer confirming evidence for the concept of a multidimensional self-concept. Significant differences were found on the seven self-concept domains of the SDQ. This result was to be expected, since the SDQ was created through work with 
Shavelson's hierarchical model of self-concept. Domain differences were also found on the Importance Scale, an instrument based on the specific self-concept areas of the SDQ. Differences in the rating of the importance of Physical, Academic and Social areas provide evidence for the multidimensionality of the importance of these domains.

An interaction of academic grouping and domain of selfconcept was found on the three and seven domain analyses of the SDQ. In concordance with the previous findings of Kelly and Colangelo (1984) and Winne, Woodlands and Wong (1982), the gifted sample rated the Academic area of self-concept higher than did their regular education peers. Within the social domain, significant differences were found in perceptions of peer relationships, with gifted children viewing their abilities in this area much lower. Interestingly, no significant differences were found in the gifted sample's ratings of the importance of the various domains. Thus, although gifted children rated their social abilities with peers as the lowest domain, this area may not impact as profoundly on their overall self-concept.

When differences in the rating of the self-concept areas within the academic groupings were examined, results were inconsistent with previous research. Contrary to Ross and Parker (1980), the gifted sample did not rate the Academic domain significantly higher than the others. Instead, the ALAP group viewed the three areas relatively equally in terms of describing themselves. Differences were found in the importance of the three dimensions, pointing to a need for further examination of these areas for each of the groups in the future. Furthermore, because no significant differences were 
found in the ALAP sample's rating of the three domains, the research of Winne, Woodlands and Wong (1982) supporting the Compensatory Model of self-concept does not hold for this research project. Clear sex differences were found with all four instruments. Stereotypical gender differences in self-concept seem already in place by the fifth grade. Within the Academic domain, females rated their Reading abilities higher than their Math abilities. Males were more confident in their Math abilities, rather than their Reading abilities. In addition, of the seven self-concept domains, the males were most confident in their physical abilities .

Interpretations of these findings point to the possibility that gender may be more of an influential variable in the formation of self-concept, as compared to gifted status. This is not to say that inclusion in a gifted program does not affect self-concept. This research did show significantly higher ratings of the academic domain by the gifted sample. A reason for this may be that this is the area that is most reinforced for bright children, through their teachers, parents, and peers. Since it is reinforced most strongly, it becomes the most salient area of the gifted child's self-concept. In contrast, teachers and parents may reinforce different areas of nongifted children's self-concepts, such as their social interactions and athletic abilities.

Kelly and Colangelo (1984) had reported differences in selfconcept as a function of sex and gifted status. This trend was not found in this research. However, non-significance in this area may be due to aspects of the gifted sample. First, the gifted sample was small. This sample consisted of a maximum of 34 individuals, with a 
similar ratio of males to females. Although this number consisted of over 50 percent of the total fifth grade gifted population, it is possible that it was too small to demonstrate significant differences. This problem was exacerbated by the decision to drop any incomplete protocols, yielding even smaller samples available for analysis. Sample size therefor varied depending on the instrument being analyzed.

An additional concept to consider as a reason for the loss of gifted status effects is the heterogeneity of gifted sample. Results from both the Who Am I? Test and the Pie Chart Instrument showed a low level of agreement within the ALAP group. A number of variables may have contributed to additional, unaccounted for variation within the ALAP group. For example, the examiner did not have access to information regarding the ALAP participants' IQ level, years of participation in the program, and participation in other enrichment programs.

The disparate sample size may have affected the analyses on the academic grouping variable as well. Sample sizes were not evenly matched for the analyses on the gifted status variable because of the limited number of ALAP participants. It was the decision of the researcher to utilize as much of the collected data as possible for each analysis, rather than to eliminate collected data. The sample sizes although not equal were close to be proportional thereby making interpretations possible.

Additional cautions regarding this project reflect the generalizability of these results. Data was collected from only one school district. This was done to control for possible differences in 
selection criteria to the gifted program. However, by attempting to control for definitional issues, generalizability to other gifted populations was minimized. As mentioned earlier, no universal definition of giftedness exists. This study utilized one particular definition of giftedness, as shown by the criteria for selection into the ALAP program. Use of participants in programs that differed in selection criteria, and therefore definition of giftedness, may have yielded different results. Additional salient variables that may have impacted on the findings include such variables as educational theory and degree of mainstreaming. Programs varying on these variables may have yielded alternate results.

Future research may attempt to take into account these definitional and sampling problems. Research using definitional criteria as an additional variable may be conducted. Schneider et al. (1989) have utilized a similar approach, although those researchers did not use an instrument designed to address multiple dimensions of self-concept.

An additional area for further research is to determine a way to link the appraisals of the self-concept domains with their relative perceived importance. The use of Harter's discrepancy formula model was not considered to be an appropriate means to analyze the instruments utilized in this research. However future research may provide a weighting method to more fully connect these aspects of self-concept and determine their influence on the global self-concept. 


\section{References}

American Psychological Association. (1981). Ethical principles of psychologists (revised). American Psychologist, 36, 633-638.

Braken, B. (1980). Comparisons of self-attitudes of gifted children and children in a nongifted, normative group. Psychological Reports, 47, 715-718.

Byrne, B.M. (1983). Investigating measures of self-concept. Measurement and Evaluation in Guidance, 16, 115-126.

Byrne, B.M. (1984). The general/academic self-concept nomological network: A review of construct validation research. Review of Educational Research, 54, 427-456.

Clark, B. (1988). Growing up gifted (3rd ed.). Columbus, OH: Merrill.

Cronbach, L.J., \& Meehl, P.E. (1955). Construct validity in psychological tests. Psychological Bulletin, 52, 281-302.

Harter, S. (1983). Developmental perspectives of the self-esteem. In P. Mussen (Ed.), Handbook of Child Psychology (Vol.4, Socialization, Personality, and Social Development pp. 275-386). New York: Wiley.

Harter, S. (1988). The construction and conservation of the self: James and Cooley revisited. In D.K. Lapsley and F.C. Power (Eds.), Self, ego, and identity: Integrative approaches (pp. 4370). NY: Springer-Verlag.

Jeske, P.J. (1985). Review of Piers-Harris Self-Concept Scale. In J.V. Mitchell (Ed.), Ninth mental measurement yearbook (pp. 11691170). Lincoln, NE: University of Nebraska Press.

Kelly, K., \& Colangelo, N. (1984). Academic and social self-concepts of gifted, general and special students. Exceptional Children, 50, 551-554.

Kuhn, M., \& McPartland, T. (1954). An empirical investigation of self-attitudes. American Sociological Review, 19, 68-76. 
Labenne, W., \& Greene, B. (1969). Educational implications of selfconcept theory. Pacific Palisades, CA: Goodyear.

Lecky, P. (1945). Self-consistency: A theory of personality. New York: Island.

Lehman, E., \& Erdwins, E. (1981). The social and emotional adjustment of young, intellectually gifted children. Gifted Child Quarterly, 25, 134-137.

Maddux, C., Scheiber, L., \& Bass, J. (1982). Self-concepts and social distance in gifted children. Gifted Child Quarterly, 26, 77-81.

Marsh, H. (1985). Age and sex effects in multiple dimensions of preadolescent self-concept: A replication and extension. Australian Journal of Psychology, 36, 367-386.

Marsh, H. (1988). Self-Description Questionnaire-1 Manual. San Antonio, TX: Psychological Corporation.

Marsh, H., Barnes, J., Cairns, L., \& Tidman, M. (1984). SelfDescription Questionnaire: Age and sex effects in the structure and level of self-concept for preadolescent children. Journal of Educational Psychology, 76, 940-956.

Marsh, H., \& Gouvernet, P. (1989). Multidimensional self-concepts and perceptions of control: Construct validation of responses by children. Journal of Educational Psychology, 11, 57-69.

Marsh, H., Parker, J., \& Smith, I. (1983). Preadolescent self-concept: Its relation to self-concept as inferred by teachers and to academic ability. British Journal of Educational Psychology, 53, 60-78.

Marsh, H., Relich, J., \& Smith, I. (1983). Self-concept: The construct validity of interpretations based upon the SDQ. Journal of Personality and Social Psychology, 45, 173-187.

Marsh, H., \& Smith, I. (1982). Multitrait-multimethod analyses of two self-concept instruments. Journal of Educational Psychology, 74, 430-440. 
Marsh, H., Smith, I., \& Barnes, J. (1984). Multidimensional selfconcepts: Relationships with inferred self-concepts and academic achievement. Australian Journal of Psychology, 36, 367-386.

Marsh, H., Smith, I., Barnes, J., \& Butler, S. (1983). Self-concept: Reliability, dimensionality, and validity, and the measurement of change. Journal of Educational Psychology, 75, 772-790.

Marx, R., \& Winne, P. (1978). Construct interpretation of three selfconcept inventories. American Educational Research Journal, 15, 99-109.

Olszewski-Kubilius, P., \& Kulieke, M. (1989). Personality Dimensions of Gifted Adolescents. In J.L. Van Tassel-Baska and P. Olzewski-Kubilius (Eds.), Patterns of influence on gifted learners: The home, the self, and the school. (pp. 125-145). NY: Teachers College Press, Columbia University.

O'Such, K., Twyla, G., \& Havertape, J. (1979). Group differences in self-concept among handicapped, normal, and gifted learners. The Humanist Educator, 18, 15-22.

Purkey, W. (1970). Self-concept and school achievement. Englewood Cliffs, NJ: Prentice-Hall.

Renzulli, J. (1978). What makes giftedness? Reexamining a definition. Phi Delta Kappan, 60, 180-184, 261.

Robinson, J., \& Shaver, P. (1973). Measures of Social Psychological Attitudes. Ann Arbor, MI: Institute for Social Research, University of Michigan.

Ross, A., \& Parker, M. (1980). Academic and social self concepts of the academically gifted. Exceptional Children, 47, 6-10.

Schneider, B.H. (1987). The gifted child in peer group perspective. New York: Springer-Verlag. 
Schneider, B.H., Clegg, M.R., Byrne, B.M., Ledingham, J.E., \& Crombie, G. (1986). The social consequences of giftedness in Ontario schools. Unpublished research report, Social Sciences and Humanities Research Council of Canada and Ontario Ministry of Education.

Schneider, B.H., Clegg, M.R., Byrne, B.M., Ledingham, J.E., \& Crombie, G. (1989). Social relations of gifted children as a function of age and school program. Journal of Educational Psychology, 81, 4856.

Shavelson, R., Hubner, J.J., \& Stanton, G.C. (1976). Self-concept: Validation of construct interpretations. Review of Educational Research, 46, 407-441.

Spitzer, S., Stratton, J., Fitzgerald, J., \& Mach, B. (1966). The selfconcept: Test equivalence and perceived validity. Sociological Quarterly, 7, 265-280.

Tannenbaum, A.J. (1986). Giftedness: A psychosocial approach. In R. Sternberg and J. Davidson (Eds.), Conceptions of Giftedness (pp. 21-52). Cambridge, England: Cambridge University Press.

Terman, L. (1925). Mental and physical traits of a thousand gifted children. In L. Terman (Ed.), Genetic Studies of Genius (Vol. I). Stanford, CA: Stanford University Press.

West, C., \& Fish, J. (1973). Relationships between self-concept and school achievement: A survey of empirical investigations. University of Illinois, Urbana-Champaign (ERIC Document Reproduction Service No. ED092 239).

Winne, P., \& Marx, R. (1981, March). Convergent and discriminant validity in self-concept measurement. Paper presented at the meeting of the American Educational Association, Los Angeles.

Winne, P., Marx, R., \& Taylor, T. (1977). Multitrait-multimethod study of three self-concept inventories. Child Development, 48, 893-901. 
Winne, P., Woodlands, M., \& Wong, B. (1982). Comparability of selfconcept among learning disabled, normal, and gifted students. Journal of Learning Disabilities, 15, 470-475.

Wylie, R. (1968). The present status of self theory. In E.A. Borgatta and W.W. Lambert (Eds.), Handbook of personality theory and research (pp. 728-787). Chicago: Rand McNally.

Wylie, R. (1974). The self-concept: A review of methodological considerations and measuring instruments. Lincoln, NE: University of Nebraska Press.

Wylie, R. (1989). Measures of self-concept. Lincoln, NE: University of Nebraska Press.

Ysseldyke, J., \& Algozzine, B. (1990). Introduction to special education. (2nd ed.). Boston: Houghton Mifflin. 
Appendix A

Research Participation Consent Form 
Daer Parant or Guerdian:

We would like to inform you that your son or daugher will be taking part In a study being conducted by the Werwick sehool Distilict. Misa Eriks Gardiner, areduate atudent at the University of Bhode Island, has designed and is conducting this research. She is being supervised by Dr. Jerry Cohen. This research hes been approved by Mr. Jeffrey sherkey, the Dlractor of Spucial services of the Harwick School District. Miss Gardiner vill also be working with Mr. Rlchard Lloyd, School Psychulogist in the Warwick school District. The purpose of this study is to improve our understending of childran's self-concepts.

This project is examining the self-concepts of fifth srade children. partlelpating children will be esked to coplete four pencil and paper beasures in the classroom, Wich should take no longer than is minutes. These neasures are well-researched instruments wich address how children see themselves. The following questions are examples of iteme that appar on one of the seasures:

I can run fasl.

I like READIXC.

I bave good muscles.

overall. I an sood at things I l1ke to do.

I. easy to like.

We believe that minimal risk is involved in this process. However, if your child feels uncomfortable during or after completion of the anasures, Miss Gardiner vill be evailable for consultation. Your child's individual performance on the messures will not affect his or her grades in the claseroom. 411 responses will be anonymous, since names will not be filled in on the veasures. The information gathered will only be looked at by the researchers. Teachers will not have access to the coupleted questionnaires.

Please note that rour permission is antirely voluntary and you are able to request thet your child does not participate. If you do not want your child to participate in this study, you and your child should aign and date the second page of this letter and return it to your child's teacher or call the school wthin 2 weeks. During the study, if your child whes to withdraw his or har participation, he or she may tell the teecher or Mis3 Cardiner.

If rou have any questions, please feel free to contact Erike Cardiner at (401) 521-7311, Dr. Cohen at (401) 792-2566, or the Vice-Provost for Research, 70 Lower college Road, the University of Rhode Island at (401) 792-2635.

Jerry L. Cohen, Ph. D.

Erike N. Gardiner 
Th: University of Rhode Island

Department of Peycholozy

Research Porticipotion Form

Self-Concepts of Fifth Grade students

I heve raad the prevlous letter and wish that wy child DoEs nor participate in the study described.

I DO rOI erant perwission for Lo perticipate in the study as described.

Signature of child

Signature of parast or guardian
Child's birthdate

Today's date

Child's teacher ard school 
Appendix B

Sample Participant Protocol 
tho An IS

Each of you is a peciel person. In some weys you ere similar to your friends. In come mys you a different. I an interested in knowing about how you see yourself. Plesse write 10 sentences thet tell be bout wo you are.

2.

2.

3.

4.

5.

6.

7.

8.

9.

20. 
I ex Interested in how inportant certain things are to you. Please read anch sentence and then check one box for each sentunce. Here are two examples that a girl nared Sarah filled out:

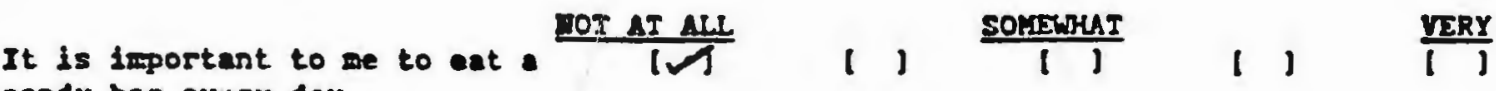
candy bar every dey.

As you can see, Sarah thinks it is not at all impotant to eat a candy bar every day.

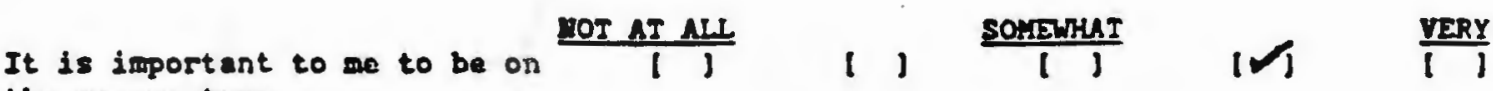
the soccer t.eam.

As you can see, it is quite important for sarah to play on the soccer toam.

yow I would like you to answar same questions about yourself, Remember to put a mark in o:ne of the boxes after each question.

\begin{tabular}{|c|c|c|c|c|c|c|c|c|c|c|}
\hline \multicolumn{3}{|c|}{ NOI AT ALI } & \multicolumn{4}{|c|}{ SOFБ:HAT } & \multirow{2}{*}{\multicolumn{2}{|c|}{13}} & \multicolumn{2}{|c|}{ VERY } \\
\hline $\begin{array}{l}\text { It is important to me to do } \\
\text { well in Reading. }\end{array}$ & 1 & 1 & $l$ & 1 & 1 & 1 & & & l & 1 \\
\hline $\begin{array}{l}\text { It is important to me to get } \\
\text { adong well with my parents. }\end{array}$ & 1 & 了 & 1 & J & 1 & 1 & 1 & 1 & 1 & J \\
\hline $\begin{array}{l}\text { It is important to me to be } \\
\text { healthy, sporty, and good- } \\
\text { looking. }\end{array}$ & $\ell$ & 了 & 1 & J & I & I & I. & 1 & 1 & J \\
\hline $\begin{array}{l}\text { It is important to me to have } \\
\text { good friends and be liked by } \\
\text { my friends. }\end{array}$ & 1 & 3 & 1 & 1 & 1 & $j$ & 1 & J & 1 & 3 \\
\hline $\begin{array}{l}\text { It is important to me to do well } \\
\text { in all my scinool subjects. }\end{array}$ & 1 & 1 & 1 & 1 & 1 & I & 1 & 3 & 1 & J \\
\hline $\begin{array}{l}\text { It is important to we to do well } \\
\text { in sports. }\end{array}$ & 1 & J & 1 & J & 1 & j & $\ell$ & נ & 1 & J \\
\hline $\begin{array}{l}\text { It is important to me to be a } \\
\text { sood student. }\end{array}$ & I & 1 & 1 & 1 & I & 1 & 1 & J & 1 & J \\
\hline $\begin{array}{l}\text { It is important to me to do well } \\
\text { in Mith. }\end{array}$ & 1 & J & 1 & J & 1 & J & I & J & 1 & J \\
\hline $\begin{array}{l}\text { It is important to se to he } \\
\text { good-200king. }\end{array}$ & I & 1 & 1 & 1 & 1 & 1 & 1 & J & $I$ & J \\
\hline $\begin{array}{l}\text { It Is lmportart to we to be liked } \\
\text { and got elong well with people. }\end{array}$ & 1 & J & 1 & 3 & 1 & I & $\mathbf{t}$ & 1 & $\mathbf{l}$ & J \\
\hline
\end{tabular}


SELF DESCRIPIION QUECIIONAIRE

Plase answer the following questions:

Your srade

Your age

Your school

Your Leacher

Circle wether you are a soY or a GIRL

\section{Circle your school activities:}

Band

Chorus

Basketbad

Drama

NLAP

Eeurpaper

Resebal1

soceer

Sefety Patrol

set

Science Falr

This is a chance lo look at yoursedf. It is not a test. There are no slsht ancwars and everyone will have different answers. Be sure that your anwers ahow how you feel sbout yourself. Please do not talk about your answers with anyone else. We will keep your answers private and not show them to anyone.

When you are ready to begin, please read each sentence and decide your answer. (You may read quietly to yourself as I read aloud.) shere are five possible answers for each question - "Irue". "Felse", and three anmers in botwan. Inere are five boxes naxt to aach sentence, one for each of the answers. The answers are witten at the top of the boxes. Choove jour answar to a sanlance and put a check mark in the box under the answer you choose. Do wot say your anmer out loud or telk about it with anyone else. 
Dafore you stert there are three axamles below. Samebody named bob has already anmered two of these eantences to show you how to do $1 t$. In the third one you wat choose jour ow answer and put in your oum chack ark.

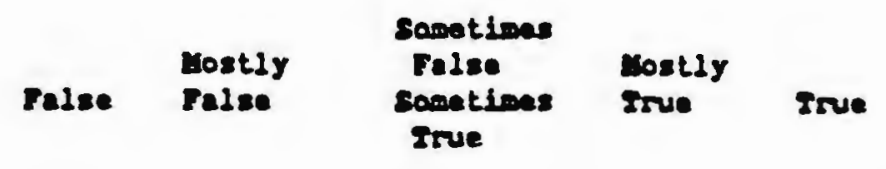

\section{-ayples}

2. I 1ike to rend comic books

$1)$

$1 \mathbf{1}$

I

I

11

(Bob put a check mark in the box under the anewer mIRUE". Ihis gens thet he really likes to resd camic books. If Bob did not like to read comic books very auch, be would heve anciured "TNLSE" of "zosILY FALE".)

2. In seneral, I am neat and tidy. ( 1

1112

$1)$

$1 \mathbf{1}$

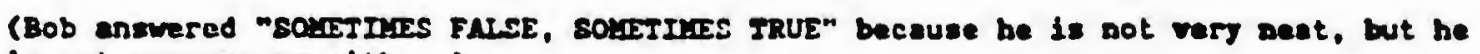
1. not very pessy either.)
3. I 11ke Lo wetch I.V.
$1 \mathbf{1}$
13
l 1
1 了
$1 \mathbf{1}$

(Fur this sentence you hove chosen the eswer that is best for you. Flrat you wut declde if the sentence is "IRUE" or "FLLSE" or somewhere in betveer. If you really like to meth I.V. a lot you would anaver "grue" by putting a check ark in the lest box. If you hate wtching $I . V$. you would anewer "Fuss" by putting a ebeck anik in the first box. If your enswer is ecmewhere in botwen then you rould choose ane of the otber three boxes.)

If you want to change an answer you buve marked you should crose out the check and put a new check in enother box on the seme 1 ine. For all the entances be sure that your ehock mork is on the onwe line os the sentence you ere engrering. You :ihould have ane answer and only ane answer for esch aentence.. Do not leave oul any of the sentences.

If you have any quektions raice your hand. Once you have atartod, Purvss Do nor בALK. 


\begin{tabular}{|c|c|c|c|}
\hline Falate! & $\begin{array}{l}\text { Must ly } \\
\text { False }\end{array}$ & 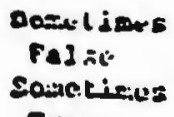 & $\begin{array}{l}\text { HusLdy } \\
\text { Irute }\end{array}$ \\
\hline
\end{tabular}

\begin{tabular}{|c|c|c|c|c|c|c|c|c|c|c|}
\hline i. & I am soon 200king & 1 & 1 & 1 & 1 & I & 1 & $i$ & J & I \\
\hline 2. & I'a sood at all schOOL surJEcT: & l & 1 & 1 & J & ! & 1 & l & 1 & t \\
\hline 3. & $I \operatorname{con} \operatorname{sun} t a x t$ & t & 1 & 1 & 1 & 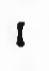 & 1 & 【 & 3 & 【 \\
\hline 4. & I get good srades In Rsaorys & 1 & 1 & 1 & 1 & 1 & 1 & I & 1 & 1 \\
\hline s. & Hy parants understand su & I & 1 & 1 & I & t & J & I & 3 & 1 \\
\hline s. & I hate EathrantJcs & 1 & ; & $\mathbf{l}$ & 1 & 1 & 1 & I & 1 & 1 \\
\hline ?. & I have lols of friends & 1 & 1 & I & $\cdot$ & 1 & I & $\mathbf{l}$ & 1 & 1 \\
\hline 8. & I like the woy I look & 1 & 1 & 1 & 1 & l & J & 1 & 1 & l \\
\hline ค. & $\begin{array}{l}\text { I cnjoy doing work in ald } \\
\text { school surJects }\end{array}$ & 1 & 1 & l & 1 & 1 & 1 & t & J & 1 \\
\hline 0. & I like to tun and play lord & I & 1 & $i$ & 1 & l & 1 & I & 1 & I \\
\hline 12. & I like REALINC & I & 1 & 1 & 1 & l & 1 & I & 1 & 【 \\
\hline
\end{tabular}

12. My parents are usuadly unhappy or disappoint.t. with what. I do

13. Wertk in MATHERATICe is cony for 2 tre

$\begin{array}{ll}1 & 1 \\ 1 & 1\end{array}$

14. I sake Elitinds eazily

11

11

l 1

l 1

11

11

2.1. I have a pleasant. 200king fact I

16. I get good grades ill ald school EURJECTS

17. I hato sports and gaies

18. $I^{\prime}=$ good at READIUG

11

29. I like sy parenc:

20. : Juok forward to LiAIHFHIIC:

11

21. Host kids have Inill friunds than I do

1,

22. I a a nice looking person

$1111: 111$

1113111

$11,1,111$

11111113

$\begin{array}{lllllll}1 & 1 & 1 & 1 & 1 & 1\end{array}$

11 1 : 111

$\begin{array}{llllllll}1 & 1 & 1 & 1 & 1 & 1 & 1 & 1 \\ 1 & 1 & 1 & 1 & 1 & 1 & 1 & 1\end{array}$




\begin{tabular}{|c|c|c|c|}
\hline & Mostly & $\begin{array}{l}\text { Sometlmes } \\
\text { False }\end{array}$ & Eost2y \\
\hline 舟 & False & $\begin{array}{l}\text { Soretimes } \\
\text { Irue }\end{array}$ & Istue \\
\hline
\end{tabular}

23. I hate al1 saHOOL SUBJECIS

111

13

l I

24. I enjoy sports and graes

11

l ]

11

11

(1)

25. I am interested in RENIUC

(1)

( )

(1)

11

11

26. Uy parents like we

1,1

l $]$

11

1 J

27. I get good grades in MTHEautics

28. I get along with other kids

essily

I

1

11

11

I J

22. I do lots of important things

30. I an ugdy

31. I learn things quickly in 211 SCHOOL SUBJECTS

$\begin{array}{llllllllll}1 & 1 & 1 & 1 & 1 & 1 & 1 & 1 & 1 & 1 \\ 1 & 1 & 1 & 1 & 1 & 1 & 1 & 1 & 1 & 0 \\ 1 & 1 & 1 & 1 & 1 & 1 & 1 & 1 & 1 & 1\end{array}$

32. I have good muscles

33. I an dumb ot READINC

34. If I have children of my own I want to bring then up like ry parents raised re

$\begin{array}{llllllllll}1 & 1 & 1 & 1 & 1 & 3 & 1 & 1 & 1 & 1 \\ 1 & 1 & 1 & 1 & 1 & 1 & 1 & 1 & 1 & 1 \\ 1 & 1 & 1 & 1 & 1 & 3 & 1 & 1 & 1 & 1\end{array}$

35. I Interested in mathmurics

36. I an easy to like

37. Overall I am no good

38. Other kids think I an good looking

1

1

11

( )

1)

(1)

( )

(1)

l)

( )

11

( )

l)

( )

l)

l)

l)

11

39. I ax interested in all SCHOOL SUBJECTE

40. I sm good at sports

( )

l $)$

l $)$

11

1 J

41. I enjoy doing work in RENDINC

1,

1

11

I

11

( )

1

( )

(1) [ ]

42. ay parents and I spend a $20 t$ of time together

1

1

11

I) 11

please continus on next page 


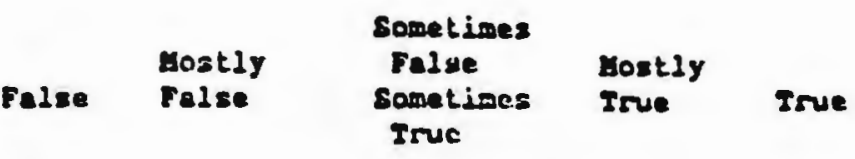

43. I learn things quickly in mmixurICS

44. Other kids want we to be their friand

I I $13,13,113$

45. In general I like being the uny I am

46. I have sood looking body

47. I andumb in all school SUBJECIS

48. I can tun a long way without stopping

49. Work in RbapIug is easy for me $($ J

51. I 1ike manghtics

52. I have wore friends then most other kids

53. Overald I have a lot to be proud of

54. I's better looking than most of my friends

55. I look forward to all schOOL

(1) 11011,113

$\begin{array}{lllllllll}1 & 1 & 1 & 1 & 1 & 1 & 1 & 1\end{array}$

\footnotetext{
SUBJECTS

56. I am good athlete

57. I look forward to rendire

58. I get along well with my parents

59. I'd good at MTHEntics

60. I a popular with kids of my orn age

62. I hate xyself

62. I have nice festures like nose and eyes and hoir
}

$\begin{array}{lllllllll}1 & 1 & 1 & 1 & 1 & 1 & 1 & 1 & 1\end{array}$

$\begin{array}{llllllllll}1 & 1 & 1 & 1 & 1 & 1 & 1 & 1 & 1 & 1 \\ 1 & 1 & 1 & 1 & 1 & 1 & 1 & 1 & 1 & 1\end{array}$

$\begin{array}{lllllllll}1 & 1 & 1 & 1 & 1 & 1 & 1 & 1 & 1\end{array}$

$\begin{array}{lllllll}1 & 1 & 1 & 1 & 1\end{array}$

$\begin{array}{llllllllll}1 & 3 & 1 & 1 & 1 & 1 & 1 & 1 & 1 & 1 \\ 1 & 1 & 1 & 1 & 1 & 1 & 1 & 1 & 1 & 1\end{array}$

$\begin{array}{lllllllll}1 & 1 & 1 & 1 & 1 & 1 & 1\end{array}$




\begin{tabular}{|c|c|c|c|}
\hline lse & Yostly & $\begin{array}{l}\text { Sometines } \\
\text { Fadse }\end{array}$ & Host $2 y$ \\
\hline & & Irve & \\
\hline
\end{tabular}

63. Work in all SCHOOL SUBJECTS

is esey for me

111101111

64. I'm good at throwing a ball

$1)$

$1)$

( )

l)

1 J

65. I bate RRADIrG

1

[ ]

[ ]

I J

11

66. Hy parants and I have a lot of fun together

$1,11,1311$,

67. I enjoy doing work in EATHEMATICS

$\begin{array}{llllllllll}1 & 1 & 1 & 1 & 1 & 1 & 1 & 1 & 1 \\ 1 & 1 & 1 & 1 & 1 & 1 & 1 & 1 & 1\end{array}$

68. Most other kids like me

I) 1

69. Overell I angood at things I like lo do

( )

l)

l)

I J

I)

70. I like all SCHOOL SUBJECTS

71. I learn things quickly in BESADIuO

1

13

(]

$1)$

I)

72. I and dumb at muthautics

i

(1)

$1)$

$1)$

(1)

( )

[ ]

l ]

Thank you for your help 
Pie Chart

I would like rou to $f 111$ in a pie chart in tarms of how you see youraelf in 3 areas. These ereas ere:

$\frac{1}{2}$

phrsicel rou

(9) nocin rou

QE) echool rou (how you do in eports, running, jumping and how you look)

(how you get along with other kids)

(how you do on school work)

Here are a couple of exangles that show you how you aight fill out such a pie chart. I asked Liss to fill in the circle below with how wuch howerk she had in 3 shool aubjects. Her pie chart looked like this:

$\begin{array}{ll}\text { Uath } & (\mathrm{H}) \\ \text { Seience } & \text { (S) } \\ \text { Reading } & \text { (R) }\end{array}$

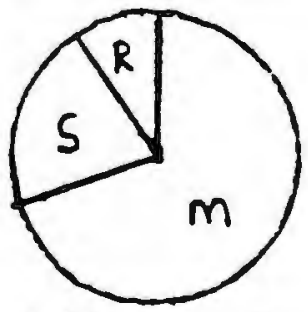

As you can see, Lisa had a lot of Eath homowork. She had less Sciance howework and only a little Reading homework.

Here is another axample. I asked Bob to fill in 3 things that he $11 k e s$ to do in his free time. If rou look at his pie chert, you will notice thet he likes to ppend some of his free time playing baseball with his friands, some timo resding books, and some tine ratching $t v$.

$\begin{array}{ll}\text { Beseball } & \text { (B) } \\ \text { Reading } & \text { (R) } \\ \text { relevision } & \text { (IV) }\end{array}$

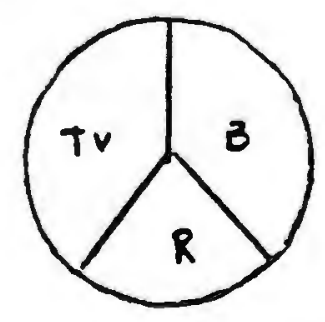


Iow I would like you to fill in a pie chart of your om. Iake a minute to think about yourself. Please fill in the circle below wh bow important each of these areas is to you. Use the letter to label the parts.

of phreicnd rou

(P)

Q) (9) socill rou

(S)

(1) achool rou

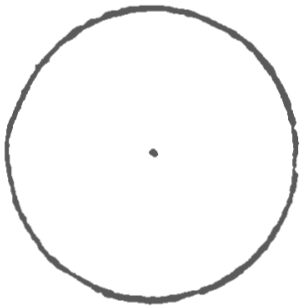




\section{Bibliography}

American Psychological Association. (1981). Ethical principles of psychologists (revised). American Psychologist, 36, 633-638.

Braken, B. (1980). Comparisons of self-attitudes of gifted children and children in a nongifted, normative group. Psychological Reports, 47, 715-718.

Byrne, B.M. (1983). Investigating measures of self-concept. Measurement and Evaluation in Guidance, 16, 115-126.

Byrne, B.M. (1984). The general/academic self-concept nomological network: A review of construct validation research. Review of Educational Research, 54, 427-456.

Clark, B. (1988). Growing up gifted (3rd ed.). Columbus, OH: Merrill.

Cronbach, L.J., \& Meehl, P.E. (1955). Construct validity in psychological tests. Psychological Bulletin, 52, 281-302.

Harter, S. (1983). Developmental perspectives of the self-esteem. In P. Mussen (Ed.), Handbook of Child Psychology (Vol.4, Socialization, Personality, and Social Development pp. 275-386). New York: Wiley.

Harter, S. (1988). The construction and conservation of the self: James and Cooley revisited. In D.K. Lapsley and F.C. Power (Eds.), Self, ego, and identity: Integrative approaches (pp. 4370). NY: Springer-Verlag.

Jeske, P.J. (1985). Review of Piers-Harris Self-Concept Scale. In J.V: Mitchell (Ed.), Ninth mental measurement yearbook (pp. 11691170). Lincoln, NE: University of Nebraska Press.

Kelly, K., \& Colangelo, N. (1984). Academic and social self-concepts of gifted, general and special students. Exceptional Children, 50, 551-554.

Kuhn, M., \& McPartland, T. (1954). An empirical investigation of self-attitudes. American Sociological Review, 19, 68-76. 
Labenne, W., \& Greene, B. (1969). Educational implications of selfconcept theory. Pacific Palisades, CA: Goodyear.

Lecky, P. (1945). Self-consistency: A theory of personality. New York: Island.

Lehman, E., \& Erdwins, E. (1981). The social and emotional adjustment of young, intellectually gifted children. Gifted Child Quarterly, 25, 134-137.

Maddux, C., Scheiber, L., \& Bass, J. (1982). Self-concepts and social distance in gifted children. Gifted Child Ouarterly, 26, 77-81.

Marsh, H. (1985). Age and sex effects in multiple dimensions of preadolescent self-concept: A replication and extension. Australian Journal of Psychology, 36, 367-386.

Marsh, H. (1988). Self-Description Questionnaire-1 Manual. San Antonio, TX: Psychological Corporation.

Marsh, H., Barnes, J., Cairns, L., \& Tidman, M. (1984). SelfDescription Questionnaire: Age and sex effects in the structure and level of self-concept for preadolescent children. Journal of Educational Psychology, 76, 940-956.

Marsh, H., \& Gouvernet, P. (1989). Multidimensional self-concepts and perceptions of control: Construct validation of responses by children. Journal of Educational Psychology, 81, 57-69.

Marsh, H., Parker, J., \& Smith, I. (1983). Preadolescent self-concept: Its relation to self-concept as inferred by teachers and to academic ability. British Journal of Educational Psychology, 53, $60-78$.

Marsh, H., Relich, J., \& Smith, I. (1983). Self-concept: The construct validity of interpretations based upon the SDQ. Journal of Personality and Social Psychology, 45, 173-187.

Marsh, H., \& Smith, I. (1982). Multitrait-multimethod analyses of two self-concept instruments. Journal of Educational Psychology, 74, 430-440. 
Marsh, H., Smith, I., \& Barnes, J. (1984). Multidimensional selfconcepts: Relationships with inferred self-concepts and academic achievement. Australian Journal of Psychology, 36, 367-386.

Marsh, H., Smith, I., Barnes, J., \& Butler, S. (1983). Self-concept: Reliability, dimensionality, and validity, and the measurement of change. Journal of Educational Psychology, 75, 772-790.

Marx, R., \& Winne, P. (1978). Construct interpretation of three selfconcept inventories. American Educational Research Journal, 15, 99-109.

Olszewski-Kubilius, P., \& Kulieke, M. (1989). Personality Dimensions of Gifted Adolescents. In J.L. Van Tassel-Baska and P. Olzewski-Kubilius (Eds.), Patterns of influence on gifted learners: The home, the self, and the school. (pp. 125-145). NY: Teachers College Press, Columbia University.

O'Such, K., Twyla, G., \& Havertape, J. (1979). Group differences in self-concept among handicapped, normal, and gifted learners. The Humanist Educator, 18, 15-22.

Purkey, W. (1970). Self-concept and school achievement. Englewood Cliffs, NJ: Prentice-Hall.

Renzulli, J. (1978). What makes giftedness? Reexamining a definition. Phi Delta Kappan, 60, 180-184, 261.

Robinson, J., \& Shaver, P. (1973). Meaures of Social Psychological Attitudes. Ann Arbor, MI: Institute for Social Research, University of Michigan.

Ross, A., \& Parker, M. (1980). Academic and social self concepts of the academically gifted. Exceptional Children, 47, 6-10.

Schneider, B.H. (1987). The gifted child in peer group perspective. New York: Springer-Verlag. 
Schneider, B.H., Clegg, M.R., Byrne, B.M., Ledingham, J.E., \& Crombie, G. (1986). The social consequences of giftedness in Ontario schools. Unpublished research report, Social Sciences and Humanities Research Council of Canada and Ontario Ministry of Education.

Schneider, B.H., Clegg, M.R., Byrne, B.M., Ledingham, J.E., \& Crombie, G. (1989). Social relations of gifted children as a function of age and school program. Journal of Educational Psychology, 81, 4856.

Shavelson, R., Hubner, J.J., \& Stanton, G.C. (1976). Self-concept:

Validation of construct interpretations. Review of Educational Research, 46, 407-441.

Spitzer, S., Stratton, J., Fitzgerald, J., \& Mach, B. (1966). The selfconcept: Test equivalence and perceived validity. Sociological Quarterly, 7, 265-280.

Tannenbaum, A.J. (1986). Giftedness: A psychosocial approach. In R. Sternberg and J. Davidson (Eds.), Conceptions of Giftedness (pp. 21-52). Cambridge, England: Cambridge University Press.

Terman, L. (1925). Mental and physical traits of a thousand gifted children. In L. Terman (Ed.), Genetic Studies of Genius (Vol. I). Stanford, CA: Stanford University Press.

West, C., \& Fish, J. (1973). Relationships between self-concept and school achievement: A survey of empirical investigations. University of Illinois, Urbana-Champaign (ERIC Document Reproduction Service No. ED092 239).

Winne, P., \& Marx, R. (1981, March). Convergent and discriminant validity in self-concept measurement. Paper presented at the meeting of the American Educational Association, Los Angeles.

Winne, P., Marx, R., \& Taylor, T. (1977). Multitrait-multimethod study of three self-concept inventories. Child Development, 48 , 893-901. 
Winne, P., Woodlands, M., \& Wong, B. (1982). Comparability of selfconcept among learning disabled, normal, and gifted students. Journal of Learning Disabilities, 15, 470-475.

Wylie, R. (1968). The present status of self theory. In E.A. Borgatta and W.W. Lambert (Eds.), Handbook of personality theory and research (pp. 728-787). Chicago: Rand McNally.

Wylie, R. (1974). The self-concept: A review of methodological considerations and measuring instruments. Lincoln, NE: University of Nebraska Press.

Wylie, R. (1989). Measures of self-concept. Lincoln, NE: University of Nebraska Press.

Ysseldyke, J., \& Algozzine, B. (1990). Introduction to special education. (2nd ed.). Boston: Houghton Mifflin. 